\title{
Speed Ripple Reduction of Direct-Drive PMSM Servo System at Low-Speed Operation Using Virtual Cogging Torque Control Method
}

\author{
Feifei Bu, Senior Member, IEEE, Zhida Yang, Yu Gao, Zihao Pan, Tianyu Pu, \\ Michele Degano, Member, IEEE, and Chris Gerada, Senior Member, IEEE
}

\begin{abstract}
This paper presents a virtual cogging torque (VCT) control method to reduce the speed ripple of direct-drive permanent magnet synchronous machine (DD-PMSM) servo system under low-speed conditions. Compared with other factors, at low speeds, the cogging torque is the main factor that deteriorates the drive performance, even induces speed oscillations. Especially in this paper, due to volume limitation, the cogging torque is designed larger than normal one in order to remove the need of brake. Based on the model of PMSM, the cause and effect of the cogging torque are analyzed. Inspired by the characteristic of cogging torque, the VCT control method is proposed and investigated to significantly reduce the speed ripple at low speeds. The main idea of this proposed control method is to produce a proper virtual cogging torque and continuously move the corresponding virtual stable equilibrium point to drive the rotor smoothly. In addition to the principle of this control method, its analysis and implementation are studied as well. Simulation and experimental results from the prototype demonstrate that the proposed control method is correct and valid, and it is simple and effective to smooth the speed at low-speed operations.
\end{abstract}

Index Terms-direct-drive servo system, permanent magnet synchronous machine, virtual cogging torque, low speed, speed ripple.

\section{INTRODUCTION}

$\mathrm{S}$ ERVO system is an important system in many applications, such as industry, aerospace, etc. It experiences the development process from hydraulic system to pneumatic system, then to electric system. In electric servo systems, the permanent magnet synchronous motor (PMSM) is widely used

Manuscript received May 6, 2019; revised July 7, 2019, October 20, 2019, accepted December 6, 2019. This work was supported in part by the National Natural Science Foundation of China under Grant 51507079, in part by the China Postdoctoral Science Foundation Funded Project under Grant 2014M560421 and Grant 2016T90454, and in part by the Fundamental Research Funds for the Central Universities of China under Grant NJ20160046 and Grant NS2018025. (Corresponding author: Feifei $\mathrm{Bu}$ )

F. Bu, Z. Yang, Y. Gao, Z. Pan and T. Pu are with Center for More-Electric-Aircraft Power System, the Key Laboratory of New Energy Generation and Power Conversion of Jiangsu Province, Nanjing University of Aeronautics and Astronautics, Nanjing 211106, China (e-mail: bufeifei1984@163.com, yangzhida_01@163.com, 15651662621 @163.com, panzihao@nuaa.edu.cn,2906877308@qq.com).

M. Degano and C. Gerada are with the Power Electronics, Machines and Control Group, University of Nottingham, NG7 2RD Nottingham, U.K. (e-mail: michele.degano@nottingham.ac.uk, chris.gerada@nottingham.ac.uk). because of its advantages: (1) high efficiency; (2) high torque density; (3) high power factor; (4) high reliability; (5) low temperature rise, etc. [1]. In some low speed applications, to achieve higher precision, the gearbox is removed from traditional PMSM servo systems. This kind of PMSM servo system is called as the direct-drive permanent magnet synchronous motor (DD-PMSM) servo system. It has the following advantages: (1) compact structure; (2) high transmission efficiency; (3) fast dynamic response; (4) high positioning accuracy; (5) low noise, etc. [2]. Therefore, the DD-PMSM servo system is increasingly employed in many fields. However, due to the lack of mechanical transmission, the speed ripple of motor will directly affect the load of the DD-PMSM servo system. It will cause the noise and shake of the load. In some extreme situations, the load may even be damaged. So, it is necessary and important to study how to decrease the speed ripple [3]-[5].

In DD-PMSM servo systems, the following factors could result in the speed ripple: (1) flux harmonics; (2) cogging torque; (3) current measurement errors; (4) dead time effect of inverter; (5) load disturbance, etc. [6]-[7]. However, in many low-speed applications, compared with other factors, the cogging torque is the main factor. As a result, many research activities have been conducted on the effect of cogging torque to reduce the speed ripple at low-speed operations [8]-[23].

From the published literature, there are mainly two approaches. One is focusing on decreasing the cogging torque itself and working on the improvement of motor design [8]-[12]. Optimizing the motor design is the most direct way to reduce the cogging torque. Common solutions include the slot skewing, pole-arc optimization, slot shifting, using of auxiliary slots or teeth, etc. However, considering the cost and complexity, many solutions are abandoned in some practical applications. The other is focusing on weakening the effect of cogging torque and working on the improvement of motor control strategy. Improving the motor control strategy is an effective and economical way in many applications, and has attracted much more attention [13]-[23].

The above second approach can be further divided into two kinds. One is the direct compensation control method based on the proportional integral (PI) controller. This control method is to generate an additional electromagnetic torque to directly offset the cogging torque [13]. It can enhance the ability of traditional PI control method to overcome the effect of cogging torque. But its performance depends on the accuracy 
of cogging torque waveform. And usually, it is difficult to obtain the accurate waveform of cogging torque in real time due to some nonlinear characteristic. The other is the improved control method based on changing the speed loop structure. [14] proposes a speed proportional-integral-resonant control strategy for low-speed high-torque PMSM drive systems. [15] uses a parameter self-learning hybrid fuzzy controller instead of a traditional PI controller to eliminate the torque ripple of PMSM. [16] proposes a closed-loop fuzzy-logic-based speed controller by using the magnitude of speed harmonic as the feedback control signal. [17] proposes an improved model predictive control based on the state observer to reduce the torque ripple of PMSM drive system caused by the cogging torque. [18] designs a speed tracking controller with an extended observer estimating the motor speed and the torque disturbances including the cogging torque. Based on above studies, these methods can reduce the speed ripple of PMSM at low speeds. However, there are still some problems, such as accuracy, adaptability, complexity, etc., which limit their applications. Therefore, they need further improvements.

As mentioned above, the cogging torque is the main factor for the speed ripple of DD-PMSM at low speeds. Especially in this paper, this situation would become more serious, that is because, considering volume limitation, the cogging torque is designed larger than normal one in order to remove the need of brake. To better solve this problem, a suitable and effective control method should be explored carefully.

Based on previous studies and the above problem, this paper proposes a novel speed-loop control method using the virtual cogging torque (VCT) to decrease the speed ripple of DD-PMSM servo system at low-speed operations. In this control method, a movable VCT is produced, and the speed loop is designed to continuously move the virtual stable equilibrium point (SEP) generated by the proper VCT at the reference speed so as to realize the speed control with the effective reduction of speed ripple. Additionally, the proposed VCT control method has the advantages of simple implementation and good adaptability.

The remainder of this paper is organized as follows. Analysis and effect of the cogging torque are presented in Section II. In Section III, the principle, analysis and implementation of the proposed control method are studied. Section IV shows some simulations and comparisons of different control methods. In Section V, the experimental results demonstrate the effectiveness of the proposed control method. Finally, some conclusions are drawn in Section VI.

\section{ANALYSIS AND EFFECT OF COGGING TORQUE}

\section{A. PMSM model}

In the $d-q$ rotating coordinate system, the mathematical model of PMSM can be achieved [24]:

$$
\begin{gathered}
{\left[\begin{array}{l}
u_{d} \\
u_{q}
\end{array}\right]=\left[\begin{array}{ll}
i_{d} & \psi_{d} \\
i_{q} & \psi_{q}
\end{array}\right]\left[\begin{array}{c}
R_{a} \\
p
\end{array}\right]+\omega_{e}\left[\begin{array}{c}
-\psi_{q} \\
\psi_{d}
\end{array}\right]} \\
{\left[\begin{array}{l}
\psi_{d} \\
\psi_{q}
\end{array}\right]=\left[\begin{array}{cc}
L_{d} & 0 \\
0 & L_{q}
\end{array}\right]\left[\begin{array}{l}
i_{d} \\
i_{q}
\end{array}\right]+\psi_{f}\left[\begin{array}{l}
1 \\
0
\end{array}\right]}
\end{gathered}
$$

where, $u_{d}$ and $u_{q}$ are the $d$-axis and $q$-axis stator voltages respectively; $i_{d}$ and $i_{q}$ are the $d$-axis and $q$-axis stator currents respectively; $\psi_{d}$ and $\psi_{q}$ are the $d$-axis and $q$-axis stator flux linkages respectively; $L_{d}$ and $L_{q}$ are the $d$-axis and $q$-axis stator inductances respectively; $R_{a}$ is the stator phase resistance; $p$ is the number of pole pairs; $\omega_{e}$ is the electrical angular velocity and $\psi_{f}$ is the magnet flux linkage.

The electromagnetic torque $T_{e}$ can be expressed as:

$$
T_{e}=\frac{3}{2} p\left[\psi_{f} i_{q}+\left(L_{d}-L_{q}\right) i_{d} i_{q}\right]
$$

From (3), it is obvious that because $L_{d}, L_{q}$ and $\psi_{f}$ are nearly constant, $T_{e}$ depends on $i_{d}$ and $i_{q}$. Based on the vector control that fixes $i_{d}$ to zero, $T_{e}$ can be rewritten as:

$$
T_{e}=\frac{3}{2} p \psi_{f} i_{q}
$$

From (4), because $p$ and $\psi_{f}$ normally keep constant, $T_{e}$ can be controlled by the $q$-axis current easily.

\section{B. Cause of cogging torque}

The cogging torque is mainly related to the structure of motor and it exists no matter whether there is current on windings or not. The cogging torque changes according to the rotor position. In some positions, the cogging torque pushes the rotor, while in some positions, it pulls the rotor, which makes the rotor keep steady in some specific positions even with a slight external torque.

Fig. 1 is the simple diagram of a PMSM with two poles and three slots. Fig. 1(a) is a stable equilibrium state, the $\mathrm{N}$ pole of magnet on the rotor is aligned with the closest stator tooth, in this state, the rotor keeps steady even with a slight external torque. Fig. 1(b) is an unstable equilibrium state, a slight external torque would drive the rotor to the state in Fig. 1(a) or Fig. 1(c). Fig. 1(c) is another stable equilibrium state, the $\mathrm{S}$ pole is aligned with the closest stator tooth.

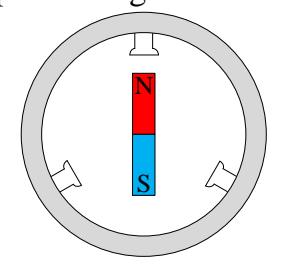

(a)

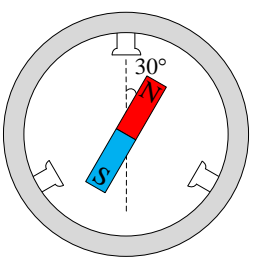

(b)

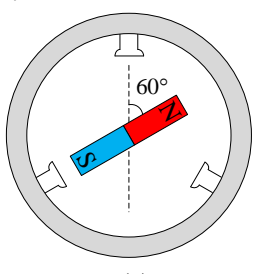

(c)
Fig. 1. Simple diagram of a 2-pole, 3-slot PMSM. (a) stable equilibrium state. (b) unstable equilibrium state. (c) another stable equilibrium state.

\section{C.Structure and cogging torque characteristic of target PMSM in this paper}

In some applications, such as aerospace, due to volume and/or weight limitations, the cogging torque of PMSM is designed larger than normal one so as to remove the need of brake, especially when there is an external torque on the rotor [25]. Also because of this, the amplitude of cogging torque of target PMSM in this paper is increased to about $70 \%$ of the rated torque, about $35 \mathrm{mNm}$ (for normal one, it is usually about 
$5 \%$ of the rated torque). This cogging torque is large enough to make the rotor of target PMSM fixed at some positions even if it suffers a slight external torque disturbance. This approach can reduce the volume and weight of whole system, however, this will increase the speed ripple of PMSM, especially influence the system performance at low speeds.

Fig. 2 shows the structure and cogging torque characteristic of the target PMSM used in this paper. This PMSM has 6 pairs of magnetic poles on the rotor and 18 slots on the stator. Taking the range of $0-\pi / 3 \mathrm{rad}$ mechanical angle as an example, the corresponding cogging torque characteristic of target PMSM in this range is also shown in Fig. 2.

According to the above analysis, for the target PMSM shown in Fig. 2, when the rotor is at the positions of $\mathrm{P}_{1}, \mathrm{P}_{3}, \mathrm{P}_{5}$, $\mathrm{P}_{7}, \mathrm{P}_{9}, \mathrm{P}_{11}$, it is like Fig. 1(b), and the motor is in unstable equilibrium states. When the rotor is at the positions of $\mathrm{P}_{2}, \mathrm{P}_{4}$, $\mathrm{P}_{6}, \mathrm{P}_{8}, \mathrm{P}_{10}$, it is like Fig. 1(a) and Fig. 1(c), and the motor is in stable equilibrium states, which means that the rotor is fixed at these positions and keeps steady. Based on this, the positions like $\mathrm{P}_{2}, \mathrm{P}_{4}, \mathrm{P}_{6}, \mathrm{P}_{8}, \mathrm{P}_{10}$ are called as the stable equilibrium points (SEPs). Correspondingly, the target PMSM in this paper has 36 SEPs.

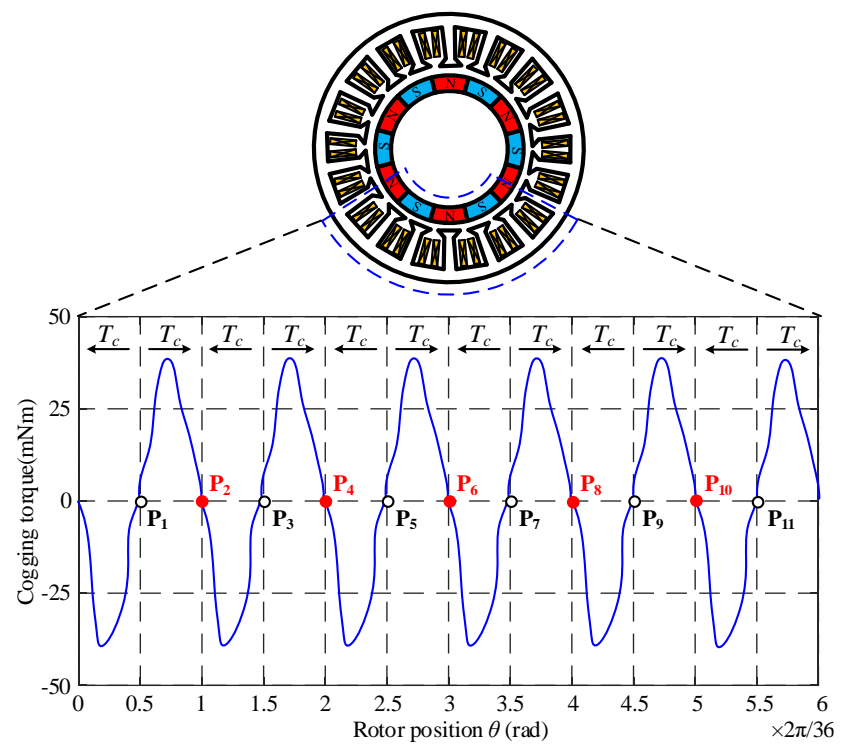

Fig. 2. Structure and cogging torque characteristic of the target PMSM used in this paper.

\section{Effect of cogging torque}

For clarity, to analyze the effect of the cogging torque, suppose: (1) there is only the cogging torque working on the motor (without external load torque); (2) the motor has already operated at an initial speed and the friction is also ignored; (3) the motor is not connected to the driver; (4) the cogging torque $T_{c}$ is simplified and expressed in (5).

$$
T_{c}=K_{c} \sin \left(N_{c} \theta+\pi\right)
$$

where, $\theta$ is the rotor position; $K_{c}$ is the amplitude of cogging torque and $N_{c}$ is the number of SEPs.

Besides, assume that the initial rotor position is 0 , the initial mechanical angular velocity is $\omega_{0}$. According to the basic equation of motion, (6) can be gotten.

$$
\left\{\begin{array}{l}
\frac{d \theta}{d t}=\omega \\
\frac{d \omega}{d t}=\frac{T_{c}}{J}
\end{array}, \theta(0)=0, \omega(0)=\omega_{0}\right.
$$

where, $J$ is the mechanical inertia of motor and $\omega$ is the mechanical angular velocity.

According to (6), Fig. 3 shows the curves of the speed influenced by the cogging torque of target PMSM with different initial speeds (in Appendix, relevant parameters are listed).

From Fig. 3, it can be seen that: (1) with the decrease of $\omega_{0}$, the frequency of speed ripple is decreasing and the amplitude of speed ripple is increasing; (2) at low speeds, the motor starts to oscillate and its average speed is zero.

The vector control with the PI controller is one of the most popular control methods used in PMSM servo systems. It usually consists of speed loop and current loop. The speed loop takes an important part in reducing the effect of cogging torque. According to [22], the load sensitivity function can be applied to analyze the speed performance in the presence of a load disturbance. To some extent, the cogging torque of PMSM can be viewed as a load disturbance, thus the load sensitivity function can also be employed to analyze the capability of the PI-based speed loop to suppress the speed ripple at low speeds.

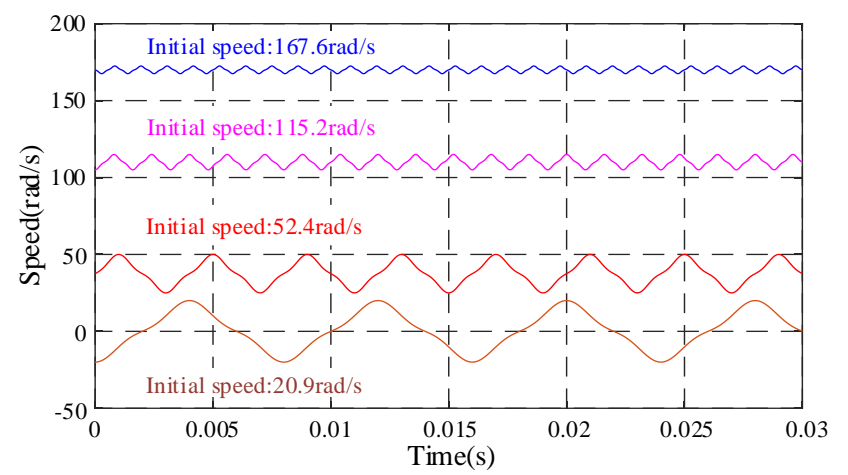

Fig. 3. Curves of the speed influenced by the cogging torque of target PMSM with different initial speeds.

Fig. 4 shows the gain spectrum of the load sensitivity transfer function for the target PMSM in this paper under the traditional PI control method (relevant parameters are given in Appendix).

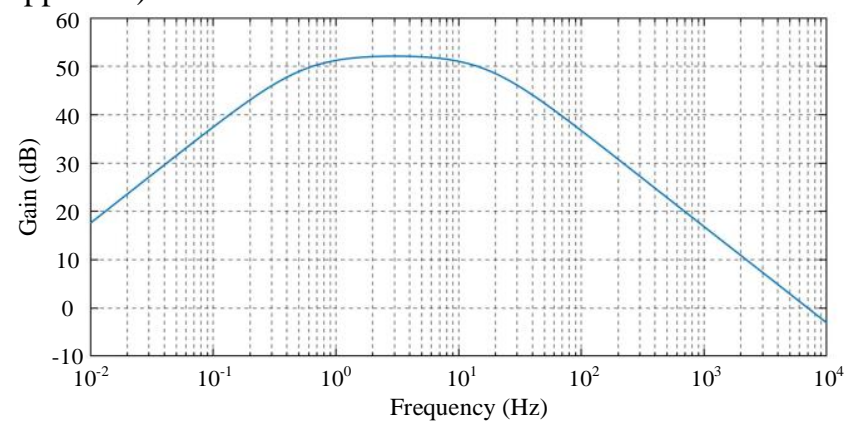

Fig. 4. Gain spectrum of the load sensitivity transfer function for the target PMSM in this paper under the PI control method. 
According to Fig. 4, the amplitude of speed ripple caused by the cogging torque at different frequencies can be obtained. As mentioned above, in this paper, the amplitude of cogging torque of target PMSM is about $35 \mathrm{mNm}$. Thus when this target PMSM operates at the low speed of $1 \mathrm{rpm}$, the changing frequency of its cogging torque is about $0.6 \mathrm{~Hz}$. At this condition, it can be seen from Fig. 4 that the corresponding gain is about $50 \mathrm{~dB}$, which means the corresponding speed ripple is about $11 \mathrm{rpm}$.

Consequently, for the target PMSM with large cogging torque, the PI-based speed loop is difficult to mitigate the effect of the low-frequency cogging torque, especially, at low speeds, it would cause larger speed ripple, even creeping problem. On the other hand, the measured speed at low speeds usually has some delay and error. And the lower the speed is, the larger the speed measurement error usually tends to be, which would further deteriorate the control performance of PI-based speed loop. Because of this, this paper mainly focuses on the speed performance improvement of target PMSM under low-speed operations.

In direct-drive servo systems, the speed ripple of PMSM works directly on the load. The speed ripple would shorten the life of a system, even damage it. So, it is necessary and meaningful to find a suitable and effective control method for the speed ripple reduction.

\section{Proposed Virtual Cogging Torque CONTROL METHOD}

\section{A. Principle of virtual cogging torque}

As analyzed above, the PMSM would start to creep at low speeds as a result of the cogging torque. When the PMSM creeps, the moving angle between adjacent creeping actions of rotor is tightly related to the cogging torque. This angle equals the distance between consecutive SEPs. So the smaller this distance is, the smaller the moving angle is, which also means a significant speed ripple reduction. The key point is that how to achieve this goal.

In general, for the PMSM, it is difficult and unrealistic to create so many SEPs to minimize the distance between them. Therefore, this paper proposes a novel VCT control method. In this method, there is a new idea that if the number of stable equilibrium points is reduced to only one (rather than increased to many enough) and this only one SEP can be continuously and smoothly moved with a small enough angle, then the speed ripple can be effectively suppressed.

For the above idea, the first and most important point is that creating a proper electromagnetic torque to make the rotor have only one SEP and fixed accurately and quickly. Inspired by the characteristic of cogging torque, and with the help of current loop, an electromagnetic torque with similar characteristic to the cogging torque (but only one SEP) can be obtained, as shown in Fig. 5. For clarity, in this paper, this electromagnetic torque is called as the VCT, and the corresponding SEP is called as the virtual SEP.

From Fig. 5, it is obvious that the rotor is fixed at this only one virtual SEP. Once the rotor deviates this point, the $q$-axis current reference becomes larger, and the VCT will drive the rotor back to the virtual SEP.

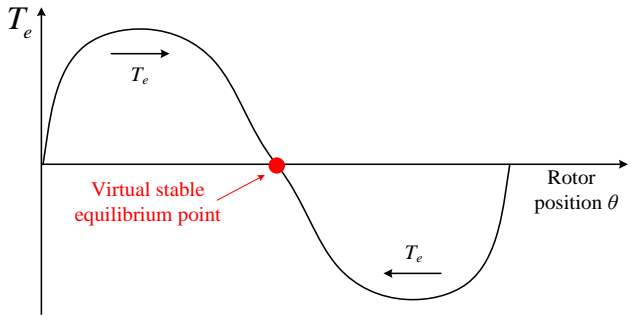

Fig. 5. Diagram of the virtual cogging torque.

To realize the speed control and speed ripple reduction, moving this virtual SEP at the reference speed can fulfill these two targets at the same time, which can be achieved by changing the $q$-axis current reference. The virtual SEP moves in each control period according to the reference speed. Because the control period of speed loop is usually quite small ( $0.5 \mathrm{~ms}$ in this paper), the moving angle (the distance that virtual SEP moves in each control period) is small enough, which allows the rotor to follow the virtual SEP smoothly, thus realizing speed control and reducing the speed ripple as last.

\section{B. Analysis of stable equilibrium point}

According to the above analysis, the generation of only one SEP is a key and important step. However, the target PMSM itself has many actual SEPs (the total number is 36) which would cause negative influence, so these actual SEPs are unexpected and needed to be eliminated. To meet this requirement, a proper VCT should be produced. For convenience of analysis, inspired by characteristic of the cogging torque, here suppose the VCT $T_{v c}$ as follow:

$$
T_{v c}=K_{v c} \sin \left(\theta+\frac{\pi}{2 N_{c}}\right)
$$

where $K_{v c}$ is the amplitude of the virtual cogging torque.

In this paper, if $K_{v c}=120 \mathrm{mNm}$, then SEPs can be obtained like Fig. 6. In Fig. 6, the red curve is the actual cogging torque, the pink curve is the VCT, and the blue curve is the resultant cogging torque, which is equivalent to the sum of the actual cogging torque and the VCT.

It can be seen from Fig. 6 that, if the generated VCT is not appropriate, obviously, there will be more than one resultant SEP (four in range from 2.6rad to 3.3rad). This range is zoomed up and shown in Fig. 6(b). In Fig. 6(b), $\mathrm{P}_{1}, \mathrm{P}_{2}, \mathrm{P}_{3}, \mathrm{P}_{4}$ are the resultant SEPs.

According to the direction of resultant cogging torque, when initial position of rotor is at different sections, the rotor would also finally be fixed at different resultant SEPs. For example, at section $\mathrm{A}$, the rotor would be finally fixed at $\mathrm{P}_{1}$. This is not expected in the position control.

The position control takes an important role in the proposed VCT control method. The performance of position control directly influences that of speed loop. Therefore, in practical applications, for the stability of the system, only one resultant SEP is needed. 
If the amplitude of VCT is increased to $500 \mathrm{mNm}$, then Fig. 7 can be obtained.
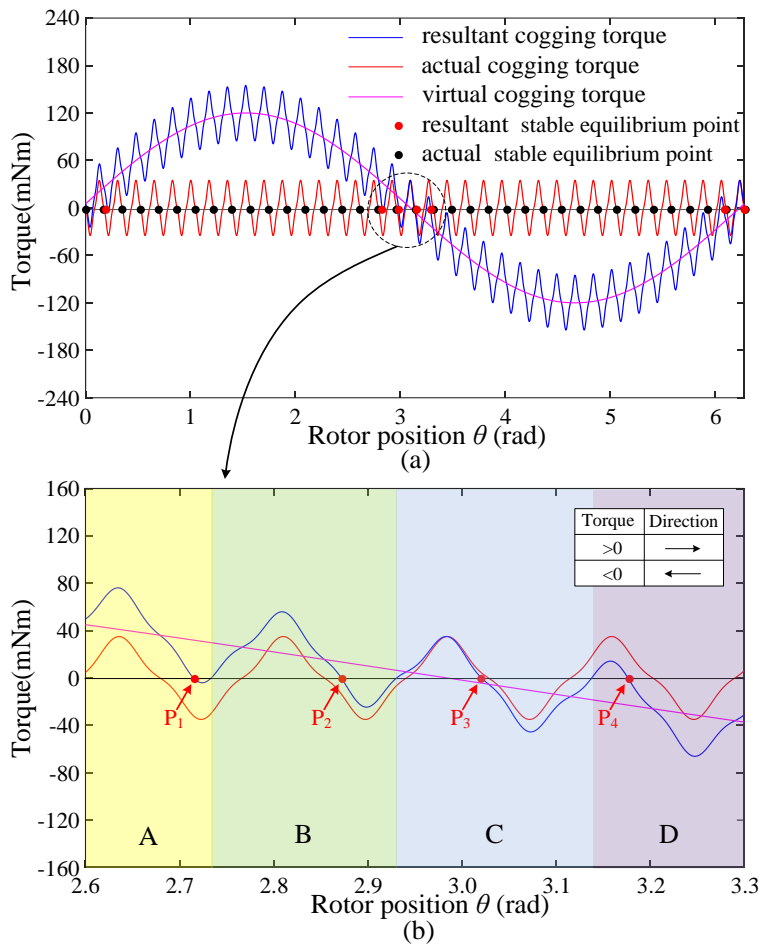

Fig. 6. Generation of several resultant stable equilibrium points. (a) Range: $0-2 \pi \mathrm{rad}$. (b) Range: 2.6 to $3.3 \mathrm{rad}$.

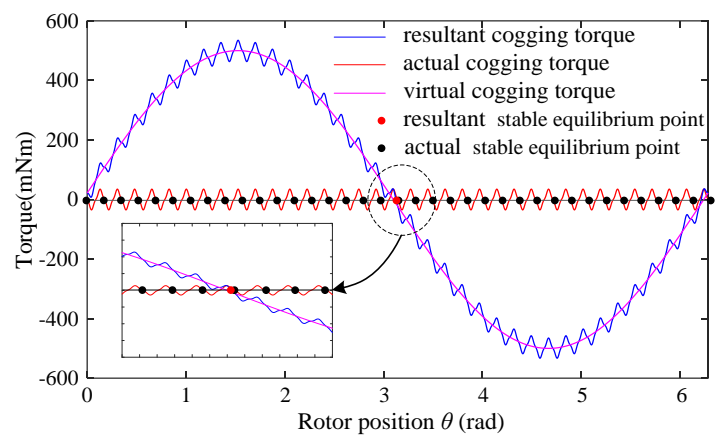

Fig. 7. Generation of the only one resultant stable equilibrium point.

From Fig. 7, with the increase of the amplitude of VCT, the number of resultant SEPs would decrease correspondingly.

The resultant cogging torque $T_{r c}$ satisfies:

$$
T_{r c}=K_{c} \sin \left(N_{c} \theta+\pi\right)+K_{v c} \sin \left(\theta+\frac{\pi}{2 N_{c}}\right)
$$

To ensure there is only one resultant SEP, (9) needs to be solved and ensured that there is only one root.

$$
K_{c} \sin \left(N_{c} \theta+\pi\right)+K_{v c} \sin \left(\theta+\frac{\pi}{2 N_{c}}\right)=0
$$

After some mathematical deviations, (10) can be obtained:

$$
\frac{K_{v c}}{K_{c}}>\frac{1}{\sin \left(\frac{2 \pi}{N_{c}}\right)}
$$

In order to use the VCT to create a virtual SEP whose position is $\theta_{\text {ref }}$, the $q$-axis current must be controlled to:

$$
i_{q}=A \sin \left(\theta_{\text {ref }}-\theta\right)
$$

where $A$ is the coefficient of VCT.

So the expression of the VCT is:

$$
T_{v c}=\frac{3}{2} p \psi_{f} A \sin \left(\theta_{r e f}-\theta\right)
$$

When the amplitude of VCT, $\frac{3}{2} p \psi_{f} A$, is much larger than that of actual cogging torque, according to the above analysis, the position of the resultant SEP $\theta_{0}$ would be near $\theta_{\text {ref }}$. In $\theta_{0}$, the following equation must be satisfied:

$$
T_{v c}+T_{c}+T_{L}=0
$$

where $T_{L}$ is the load torque.

From (12) and (13), it can be deduced that:

$$
\theta_{0}=\theta_{r e f}+\arcsin \left(\frac{2\left(T_{c}+T_{L}\right)}{3 p \psi_{f} A}\right)
$$

It is obvious that there is an error $e_{x}$ between the position of virtual SEP $\theta_{r e f}$ and that of resultant SEP $\theta_{0}$.

$$
e_{x}=\arcsin \left(\frac{2\left(T_{c}+T_{L}\right)}{3 p \psi_{f} A}\right)
$$

Because in this paper, the resultant SEP is used to drive the rotor moving, the position of resultant SEP must be controllable. To realize this target, the resultant SEP must be as close as possible to the virtual SEP. From (15), increasing $A$ is an efficient and simple way to reduce this error. However, in practical applications, to protect the motor and driver, the motor current must be limited, which means the amplitude of VCT must be limited as well. Therefore, considering the maximum allowable current, the corresponding curve of VCT is shown in Fig. 8.

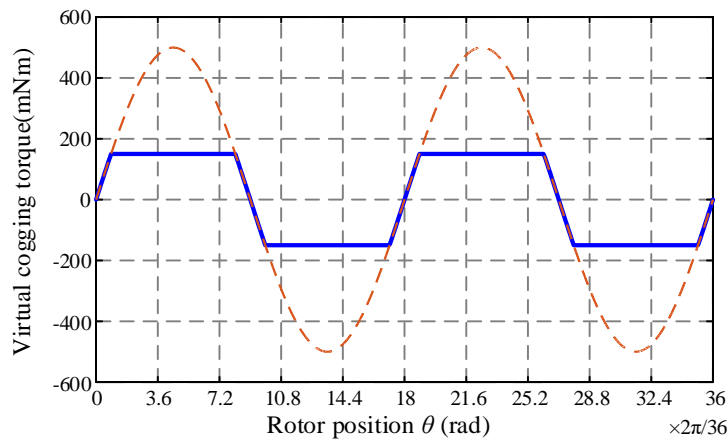

Fig. 8. Virtual cogging torque considering the current limit.

\section{C.Speed control principle with virtual cogging torque}

\section{(1) Move of virtual stable equilibrium point}

According to the above analysis, if the amplitude of VCT is large enough, then the effect of actual cogging torque can be neglected, and the virtual SEP can be considered as the only one resultant SEP.

Since the rotor can be fast fixed at the virtual SEP using the VCT, to achieve the speed control, this point must move at the reference speed. If the reference speed is $\omega_{\text {ref }}$, then this point would move like Fig. 9. The movement can be expressed as:

$$
\theta_{\text {ref }}=\left(\theta_{\text {ref }}{ }^{\prime}+\omega_{r e f} \Delta t\right)
$$


where, $\theta_{\text {ref }}$ and $\theta_{\text {ref }}$ ' are the positions of virtual SEP in this and last control period respectively; $\Delta t$ is the control period of speed loop. $\omega_{\text {ref }} \Delta t$ equals the distance that virtual SEP moves in each control period, namely the moving angle, as shown in Fig. 9. As mentioned above, the control period of speed loop in this paper is very small, so the moving angle correspondingly is also quite small. When the virtual SEP moves, it would drive the rotor to move smoothly, then the speed of rotor equals the speed of this point $\left(\omega_{\text {ref }}\right)$. Therefore, the speed control can be achieved.

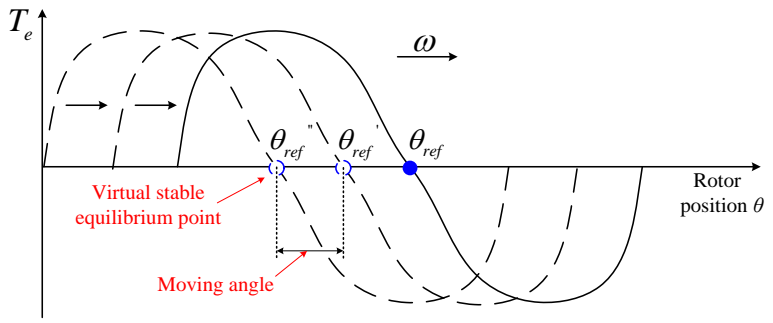

Fig. 9. Speed control by moving the virtual stable equilibrium point.

\section{(2) Elimination of oscillation caused by virtual cogging torque}

By adjusting the $q$-axis current reference in each control period, the virtual SEP can move at the reference speed smoothly. However, only using the VCT like Fig. 8 would cause the oscillation of rotor, as shown in Fig. 10 and Fig. 11.

In fact, this kind of oscillation also exists when there is only the actual cogging torque working on the motor. However, due to actual damping like friction, the rotor tends to enter in the stable equilibrium state quickly. Because the amplitude of VCT is much larger than that of actual cogging torque, the actual damping is no longer effective. Learning from this phenomenon, adding a virtual damping is a useful way to eliminate the oscillation caused by the VCT.

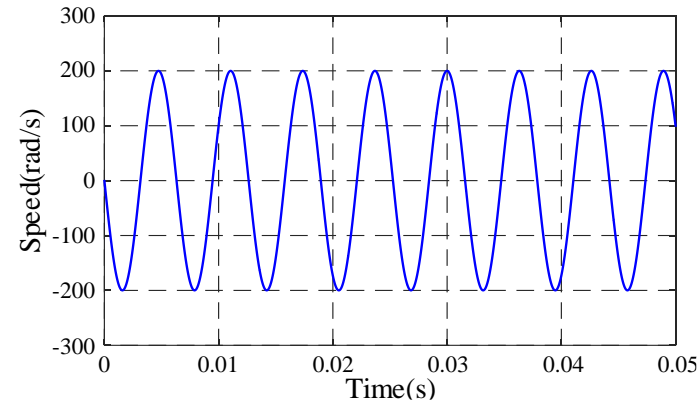

Fig. 10. Speed oscillation caused by the virtual cogging torque.

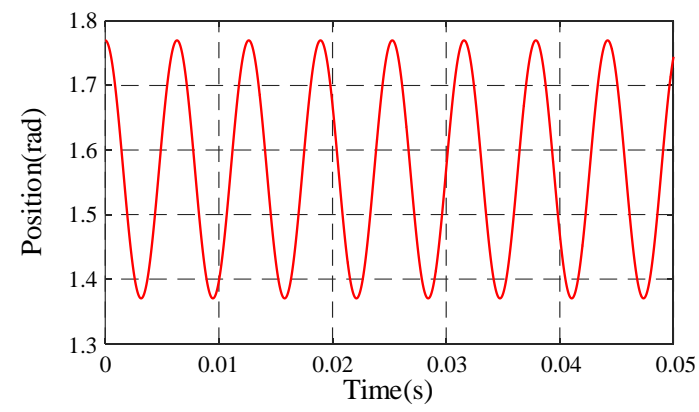

Fig. 11. Position oscillation caused by the virtual cogging torque.
To achieve this goal, the virtual damping must be related to the speed. When the motor speed is larger than its reference, the $q$-axis current reference needs to be decreased. When the motor speed is smaller than its reference, the $q$-axis current needs to be increased. So, the $q$-axis current reference corresponding to the virtual damping $i_{q r e f-v d}$ should be:

$$
i_{\text {qref-vd }}=k\left(\omega_{\text {ref }}-\omega\right)
$$

where, $k$ is the coefficient of virtual damping.

Finally, by combining the virtual cogging torque part and the virtual damping part, the $q$-axis current reference can be gotten as follows:

$$
i_{\text {qref }}=A \sin \left(\theta_{\text {ref }}-\theta\right)+k\left(\omega_{\text {ref }}-\omega\right)
$$

Obviously, the expression of $q$-axis current reference does not have the integral action of speed error, so unlike the PI controller, the calculation error of speed would not be accumulated. What's more, the $q$-axis current reference generated by the proposed control method mainly relies on the position signal, and the speed signal is just auxiliary (without strict precision requirement of speed). Therefore, the speed loop using the VCT control method could be effective to reduce the speed ripple at low speeds.

\section{Implementation of proposed VCT control method}

Fig. 12 shows the PMSM control method based on the proposed VCT control method. In Fig.12, there are two kinds of control loops: speed loop and current loop. The speed loop is based on the VCT control method. Both $d$-axis and $q$-axis current loops are traditional ones.

\section{(1) Implementation of Speed loop}

In this proposed control method, the implementation of speed loop mainly has the following four steps.

Step 1: Calculation of stable equilibrium point position

The Block A is applied to calculate the position of virtual SEP $\theta_{r e f}$ according to (16). By using this Block A, the speed reference $\omega_{\text {ref }}$ is converted to $\theta_{r e f}$. When the motor starts, the initial value of $\theta_{\text {ref }}$ equals the initial rotor position. In this paper, the position sensor is an absolute encoder, so the initial rotor position can be read from the absolute encoder directly. If the position sensor is an incremental encoder, like other control methods, some existing ways can also be employed to obtain the initial rotor position. For example, [26] estimates the initial rotor position by applying a position observer; [27] gets the initial rotor position by injecting proper high frequency pulsating voltage signals.

Step 2: Calculation of virtual cogging torque current

The Block B is employed to calculate the $q$-axis current reference corresponding to the VCT by (11). The VCT is only related to the position error. To generate only one resultant SEP, the amplitude of VCT $K_{v c}$ needs to satisfy (10).

Considering $K_{v c}$ can be written as (19),

$$
K_{v c}=\frac{3}{2} p \psi_{f} A
$$




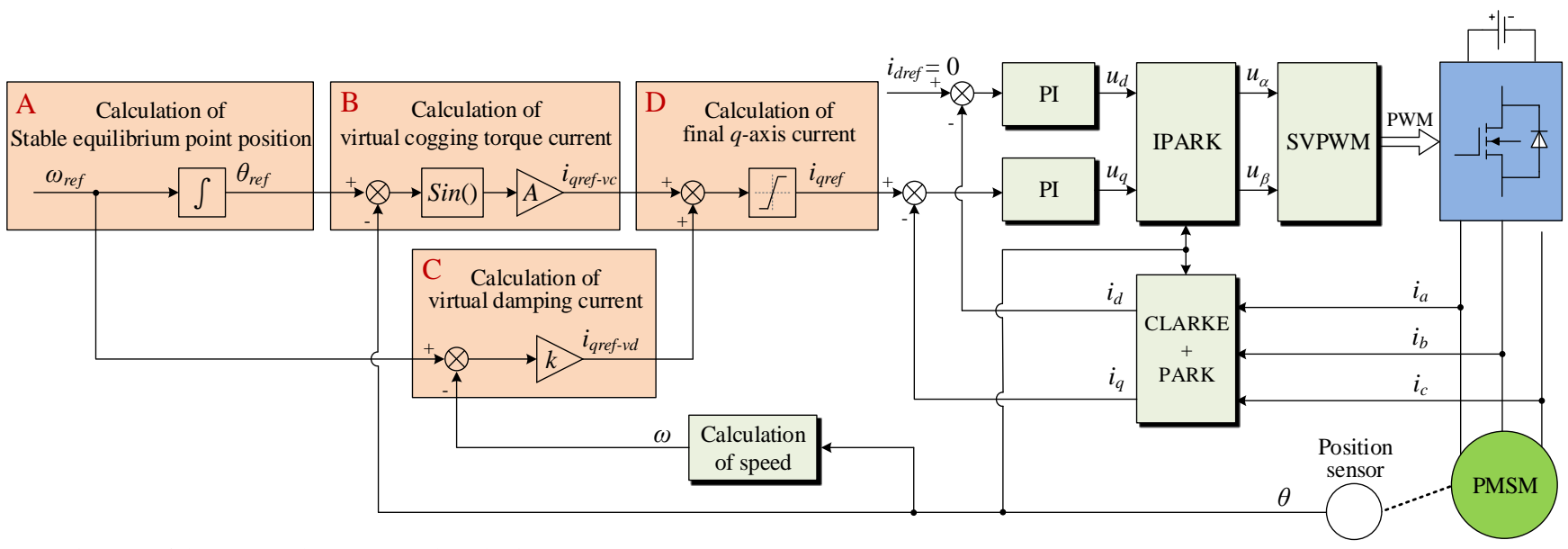

Fig. 12. Diagram of the proposed VCT control method.

So, $A$ needs to satisfy (20)

$$
A>\frac{K_{c}}{1.5 p \psi_{f} \sin \left(\frac{2 \pi}{N_{c}}\right)}
$$

where, $N_{c}$ can be gotten according to number of pole pairs and slots; $K_{c}$ can be measured by using a dynamometer to pull the rotor until the rotor moves (The maximum force recorded corresponds to the amplitude of cogging torque.).

Based on the Block B, a virtual SEP whose position is $\theta_{r e f}$ can be generated.

\section{Step 3: Calculation of virtual damping current}

The Block $\mathrm{C}$ is used to calculate the $q$-axis current reference corresponding to the virtual damping with the help of (17). For the virtual damping coefficient $k$, because the proposed control method does not need the precise virtual damping, $k$ is mainly determined by simulations and experiments. Through the Block $\mathrm{C}$, the oscillation of rotor caused by the VCT can be eliminated.

Step 4: Calculation of final $q$-axis current.

The Block D generates the final $q$-axis current reference using (18) which has two parts: virtual cogging torque part and virtual damping part, obtained in above Step 2 and Step 3. To protect the motor and driver, a proper current limit is also necessary in this block. For the maximum $q$-axis current reference $i_{q \text {-max }}$, it is designed according to the maximum allowable torque of target PMSM.

\section{(2) Implementation of Current loop}

In the current loop, two traditional PI controllers are used for the regulations of $d$-axis and $q$-axis currents. The corresponding loop function is given in Fig. 13 [28].

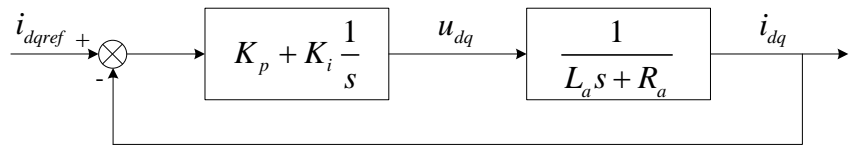

Fig. 13. Loop function of $d q$-axis current loop using PI controller.

The open loop transfer function $G_{o}(s)$ of the above current loop is:

$$
G_{o}(s)=\left(K_{p}+K_{i} \frac{1}{s}\right) \frac{1}{L_{a} s+R_{a}}=\frac{K_{p} s+K_{i}}{s\left(L_{a} s+R_{a}\right)}
$$

where, $K_{p}$ and $K_{i}$ are the proportion coefficient and integral coefficient of PI current controller respectively; $L_{a}$ is the phase inductance.

Using a zero point of open loop transfer function to cancel out one of its pole points, (22) can be gotten:

$$
\frac{K_{p}}{K_{i}}=\frac{L_{a}}{R_{a}}
$$

Then, the close loop transfer function of current loop is:

$$
G_{c}(s)=\frac{1}{\frac{L_{a}}{K_{p}} s+1}
$$

According to amplitude gain of above close loop transfer function, (24) can be obtained.

$$
\left\{\begin{array}{l}
K_{p}=1.5535 \omega_{b} L_{a} \\
K_{i}=1.5535 \omega_{b} R_{a}
\end{array}\right.
$$

where $\omega_{b}$ is the designed bandwidth. In this paper, the bandwidth of current loop is about $12560 \mathrm{rad} / \mathrm{s}(2 \mathrm{kHz})$.

Based on theoretical calculation and analysis, the practical PI parameters of current loop need to be further adjusted according to simulations and experiments, then they can be finally obtained.

\section{(3) Low speed measurement method}

According to (18), $i_{\text {qref }}$ mainly depends on the virtual cogging torque part, and the virtual damping part is just auxiliary, which means the precise speed feedback is not needed. Therefore, in this paper, the speed measurement can be accomplished by simply calculating the position change of rotor in each control period of speed loop, namely the following (25), then speed information can be obtained.

$$
\omega=\frac{\Delta \theta}{\Delta t}
$$

where $\Delta \theta$ is the position change of rotor in each control period of speed loop. 


\section{Simulation RESULTS}

To verify the proposed control method, some comparative simulations and discussions are carried out.

\section{A. Simulation of proposed control method}

Using MATLAB/Simulink, the simulation model is established. The speed reference is $1 \mathrm{rpm}$, and the load torque is $50 \mathrm{mNm}$ (rated torque). Other parameters are listed in Appendix. Fig. 14 shows the simulation results of the proposed VCT control method with the rated load at the speed of $1 \mathrm{rpm}$.

From Fig. 14, using the proposed VCT control method, when the PMSM moves at the speed of $1 \mathrm{rpm}$, there is no creeping problem, and the speed ripple is relatively small. The simulation result of rotor position shows that the rotor follows the virtual SEP quickly when the virtual SEP moves at the speed of $1 \mathrm{rpm}$ according to (16). Besides, as analyzed above, the $q$-axis current indeed consists of two parts: virtual cogging torque part and virtual damping part. From simulation results of torque and current, the electromagnetic torque and $q$-axis current are not too large and also do not reach or exceed the maximum allowed values because the rotor position would not change too much in each control period, instead, they match the cogging torque and load torque well. Therefore, the speed loop using the VCT control method is valid for the speed ripple reduction at the speed of $1 \mathrm{rpm}$.
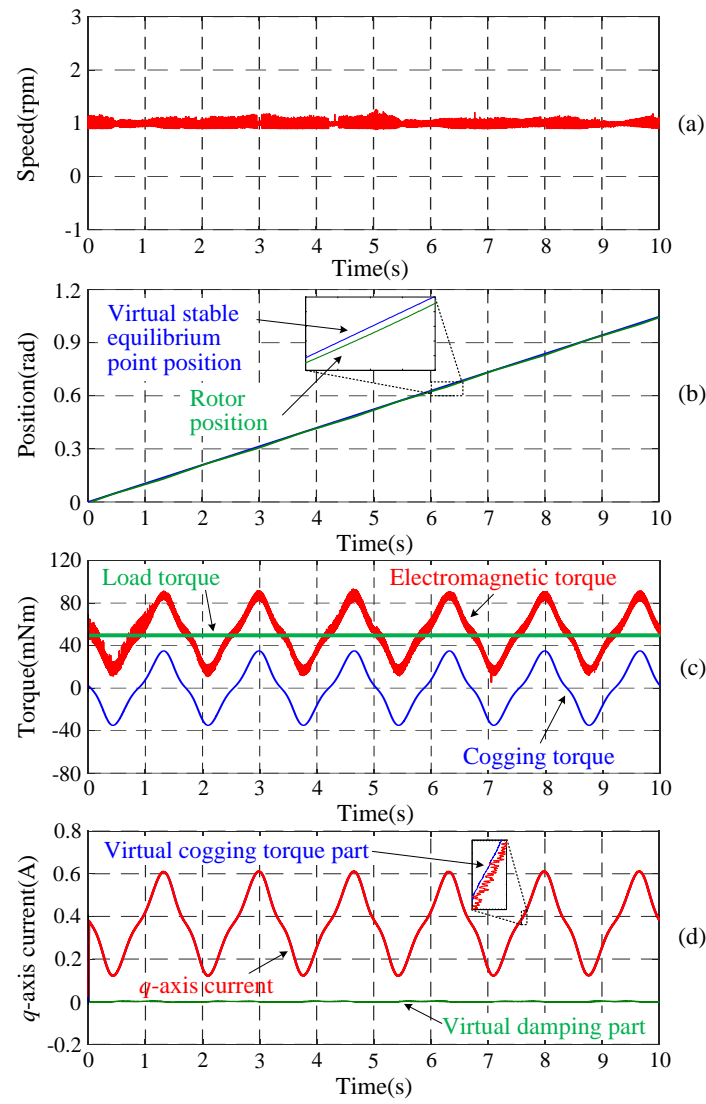

Fig. 14. Simulation results of the proposed VCT control method with the rated load at the speed of 1rpm.(a) Speed. (b) Position. (c) Torque.(d) $q$-axis current.

\section{B. Comparison of different control methods}

(1) Speed performance of PI control method for different PMSMs under the rated condition
To test the effect of such large cogging torque on the speed performance, some simulations are carried out under the rated condition using the PI control method for two PMSMs with different cogging torque characteristics. One is the conventional PMSM with the normal cogging torque of 5\% of the rated torque; the other is the target PMSM with the large cogging torque of $70 \%$ of the rated torque. And other parameters of them are nearly the same. The corresponding simulation results are shown in Fig. 15.

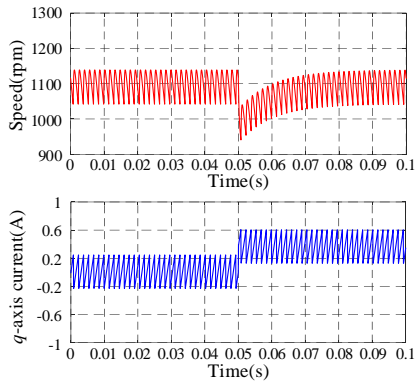

(a)

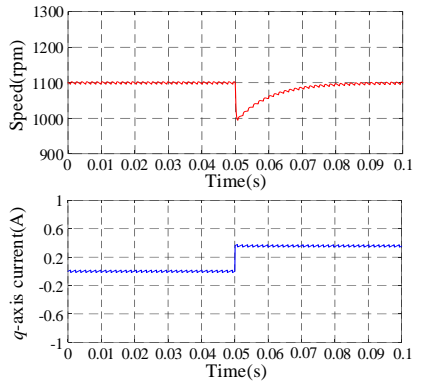

(b)
Fig. 15. Simulation results of the PI control method at the rated speed with the rated load for two PMSMs with different cogging torque characteristics. (a) Cogging torque: $5 \%$ of the rated torque. (b) Cogging torque: $70 \%$ of the rated torque.

From Fig. 15, under the rated condition, compared with the PMSM with small cogging torque, that with large cogging torque has a little larger speed ripple, but their transient performances are nearly similar.

(2) Power consumption of different control methods at the same operation point

The power consumption is an important index for motor driver. In this paper, a DC power source of $31 \mathrm{~V}$ is used. Fig. 16 and Table. I give the simulation results of DC bus currents for three different methods at the same operation point (with the same load and at the same speed). From Fig. 16, the DC bus current is similar to the $q$-axis current because the DC bus voltage is constant and the $d$-axis current is about zero. Moreover, from Table. I, under the same condition, the RMS values of DC bus currents for above three methods are very close, which means the difference of their power consumptions is very small.

Table. I. RMS values of DC bus currents for different control methods with the rated load at the speed of $1 \mathrm{rpm}$.

\begin{tabular}{|c|c|}
\hline Control method & RMS value of DC bus current (A) \\
\hline PI & 0.378 \\
\hline Direct compensation & 0.385 \\
\hline VCT & 0.402 \\
\hline
\end{tabular}

(3) Speed performance of different control methods for the conventional PMSM at low speed

To verify the effectiveness of proposed control method for the conventional servo motor, some simulations of different control methods for the PMSM with normal cogging torque (5\% of the rated torque) are carried out. The speed reference is $1 \mathrm{rpm}$, and the corresponding simulation results are shown in Fig. 17. In simulations, except for the cogging torque, other parameters of this PMSM are nearly the same as those of the target PMSM in this paper.

From Fig. 17, compared with other two control methods, the proposed VCT control method has a smaller speed ripple, so it also can be applied to conventional servo motors. 

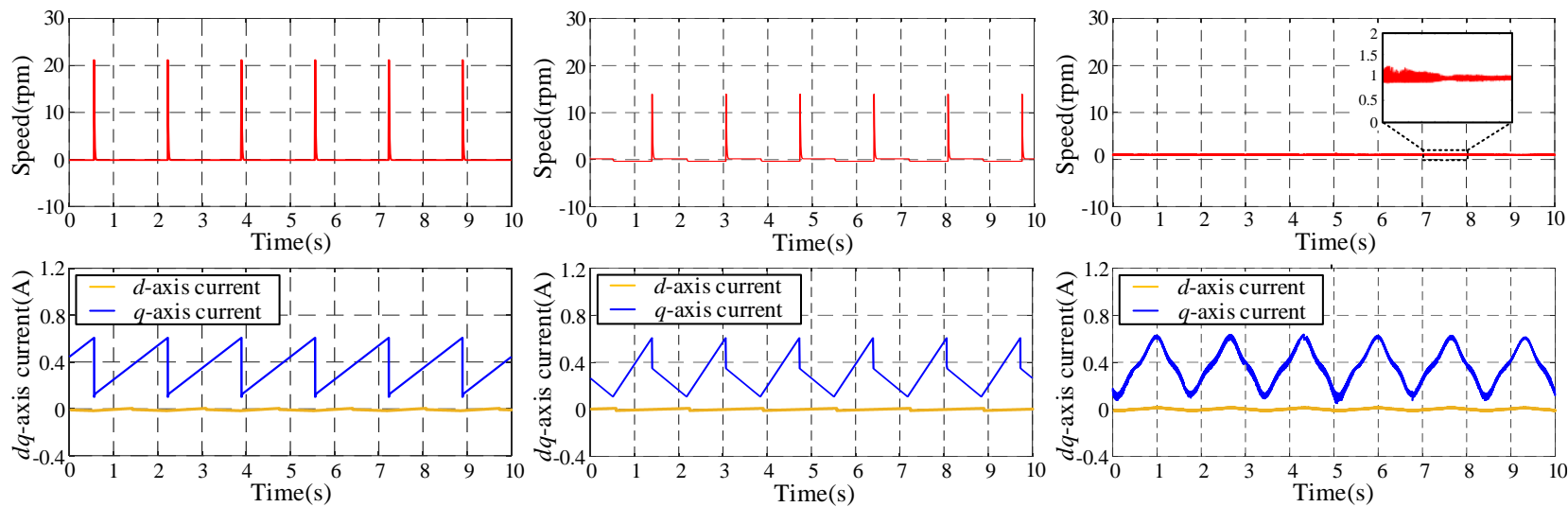

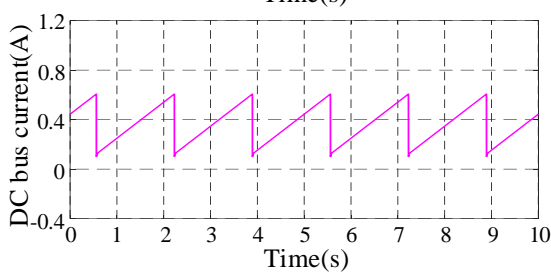

(a)

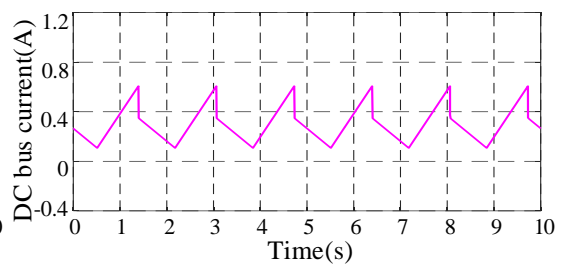

(b)

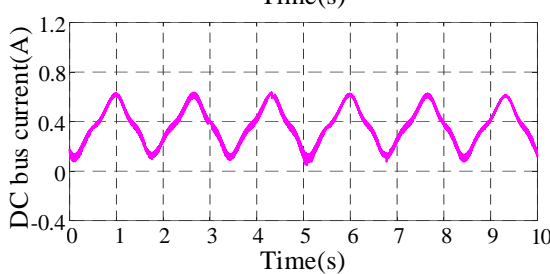

(c)

Fig. 16. Simulation results of the DC bus current for different control methods with the rated load at the speed of 1rpm.

(a) PI control method. (b) Direct compensation control method. (c) Proposed VCT control method.
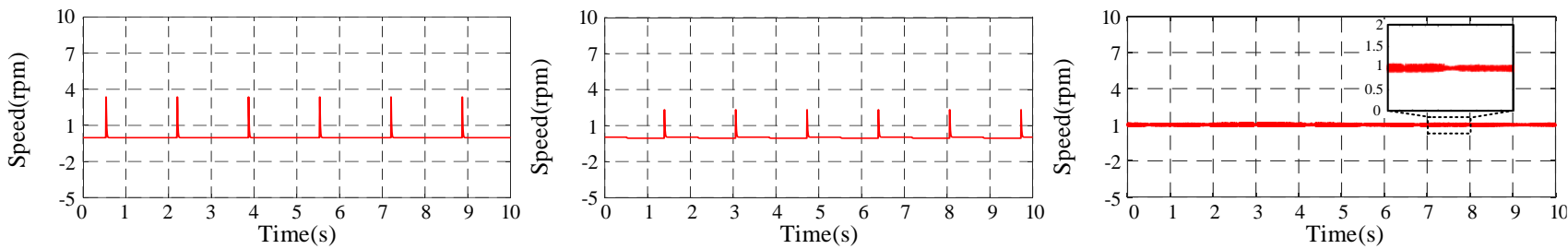

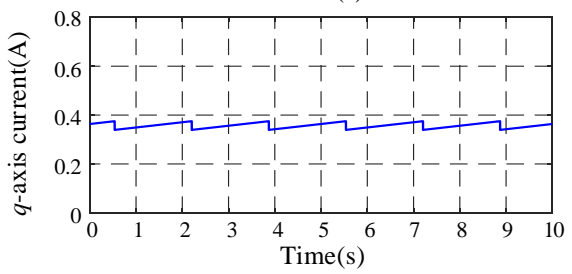

(a)

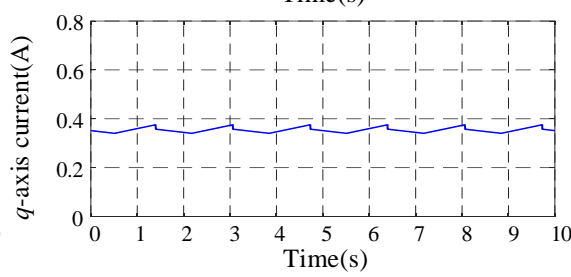

(b)

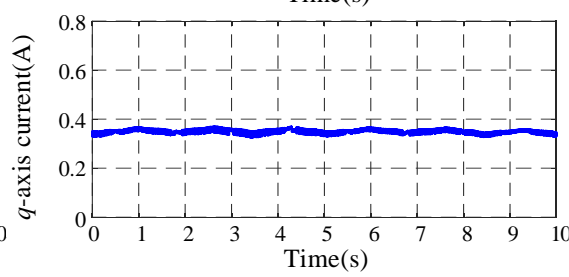

(c)

Fig. 17. Simulation results of different control methods used on conventional servo motor at the speed of $1 \mathrm{rpm}$ with the rated load. (a) PI control method. (b) Direct compensation control method. (c) Proposed VCT control method.

(4) Speed performance of different control methods for the target PMSM with the rated load at different speeds

Fig. 18-Fig. 21 show the simulation results of the speed performance of different control methods for the target PMSM with the rated load at different speeds (1100rpm (rated speed), 100rpm, 10rpm, 1rpm respectively).
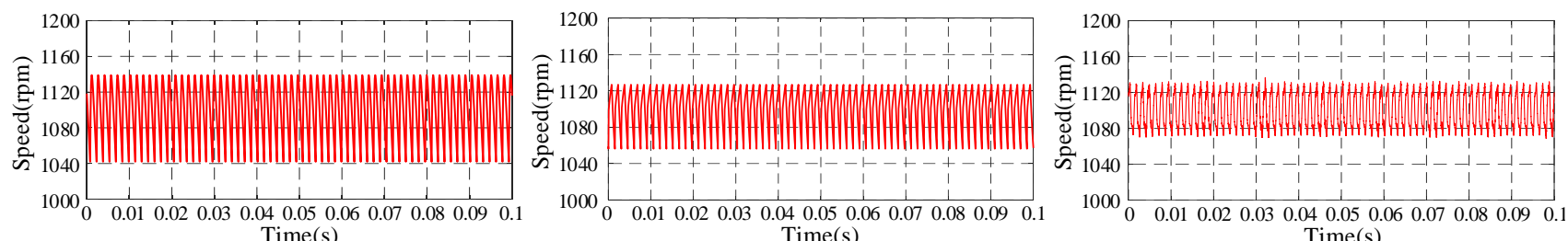

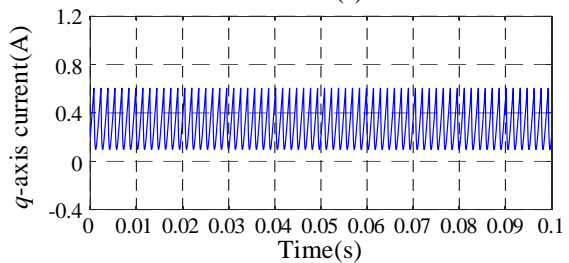

(a)

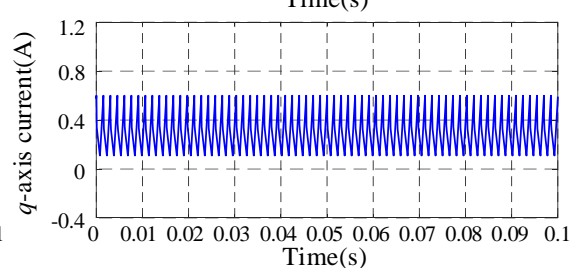

(b)

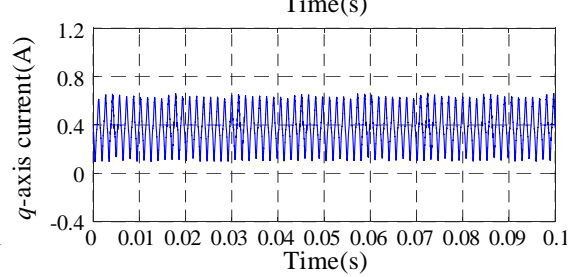

(c)

Fig. 18. Simulation results of different control methods at the rated speed of 1100rpm with the rated load. (a) PI control method. (b) Direct compensation control method. (c) Proposed VCT control method. 

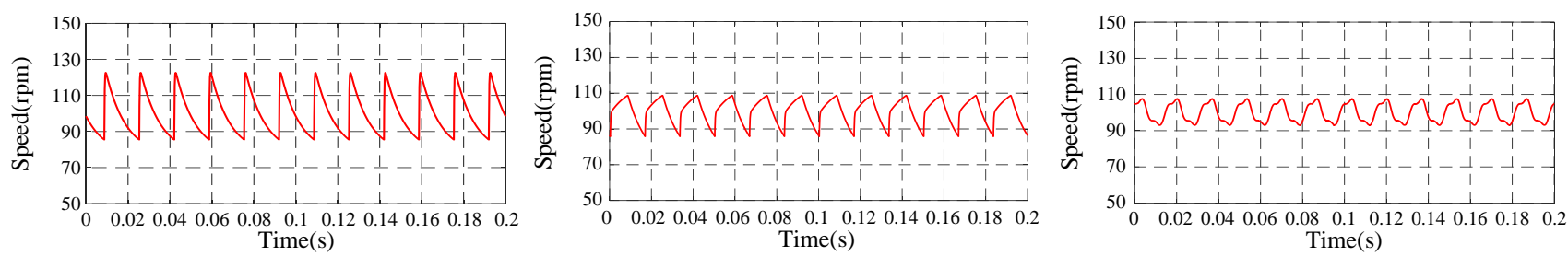

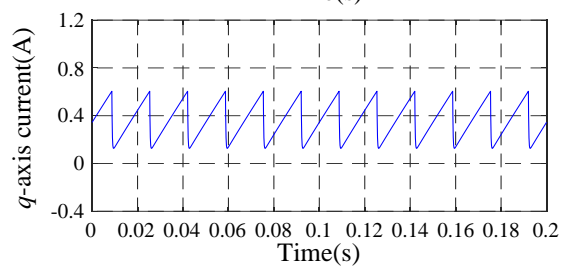

(a)

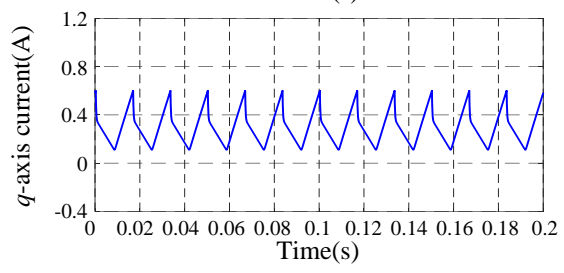

(b)

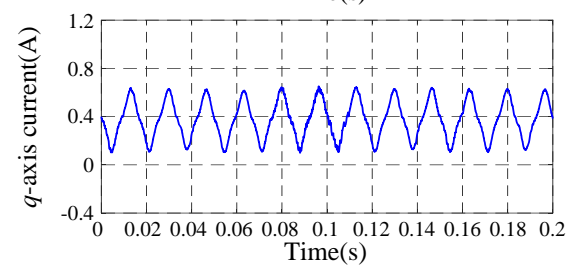

(c)

Fig. 19. Simulation results of different control methods at the speed of 100rpm with the rated load

(a) PI control method. (b) Direct compensation control method. (c) Proposed VCT control method.
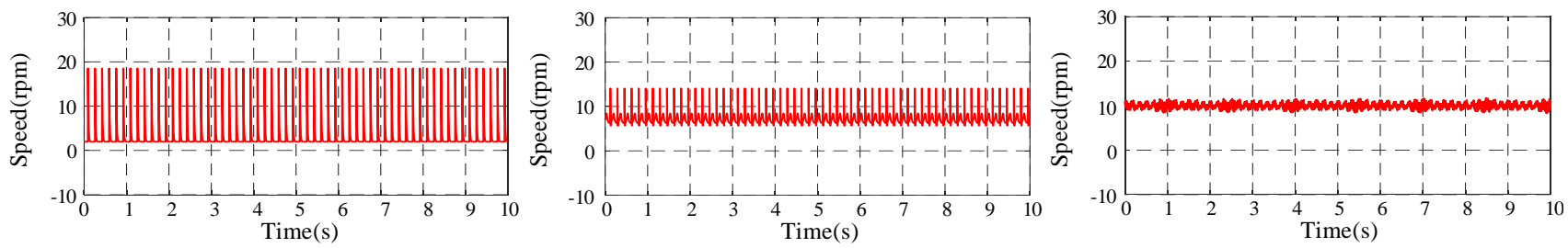

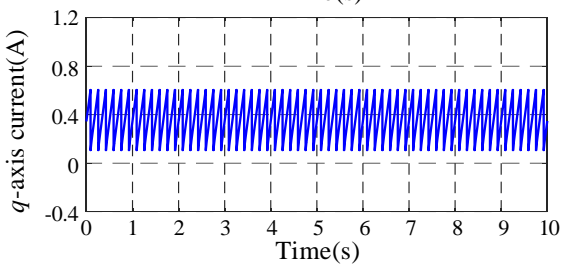

(a)

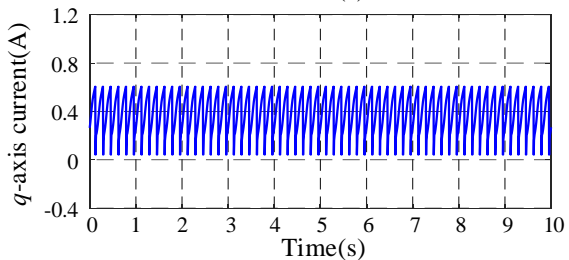

(b)

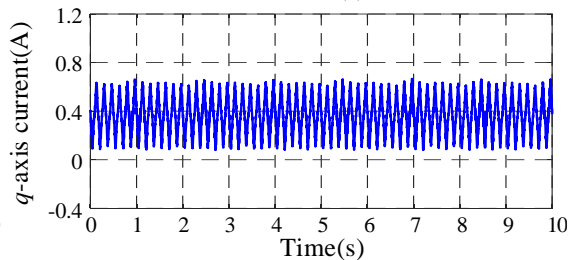

(c)

Fig. 20. Simulation results of different control methods at the speed of 10rpm with the rated load.

(a) PI control method. (b) Direct compensation control method. (c) Proposed VCT control method.
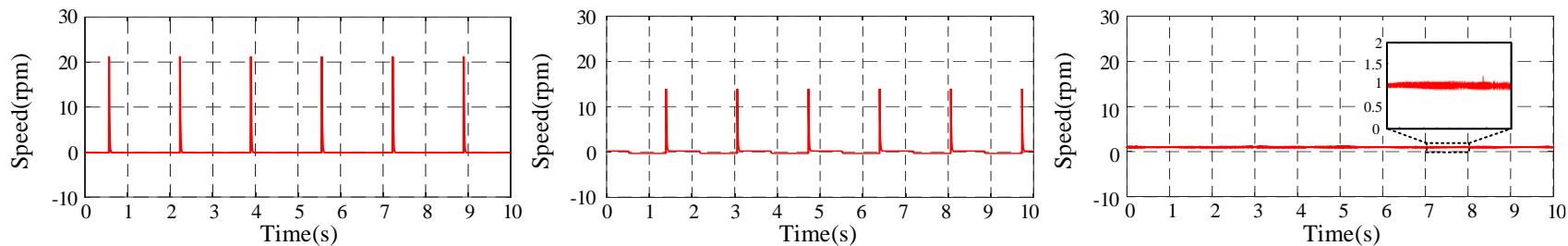

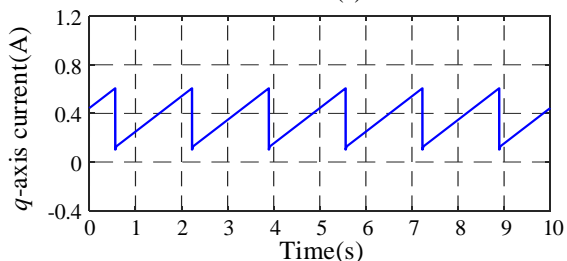

(a)

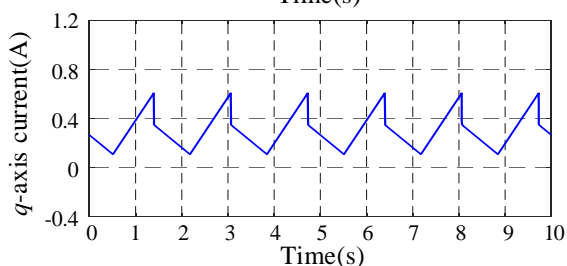

(b)

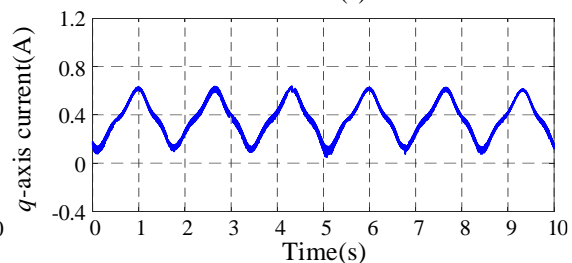

(c)

Fig. 21. Simulation results of different control methods at the speed of 1rpm with the rated load.

(a) PI control method. (b) Direct compensation control method. (c) Proposed VCT control method.

It can be seen from above simulation results that: (1) at low speeds, it is hard for the PI control method and direct compensation control method to overcome the effect of large cogging torque in the target PMSM, while the proposed control method can effectively reduce the speed ripple; (2) compared with high-speed conditions, under low-speed conditions, the effect of large cogging torque on the speed ripple is more serious, and even would cause creeping problem. Because of this, this paper mainly focuses on the speed performance of the proposed control method at low speeds, especially for $1 \mathrm{rpm}$.

\section{EXPERIMENTAL RESULTS}

For further demonstrating the proposed control method, an experimental prototype has been developed, as shown in Fig. 22 and Fig. 23. The speed loop based on the proposed control method and the current loop are implemented in a DSP and a FPGA respectively. The diver consists of a integrated power 
module. The supply is a DC power source of $31 \mathrm{~V}$. The detailed parameters of this experimental prototype are listed in Appendix.

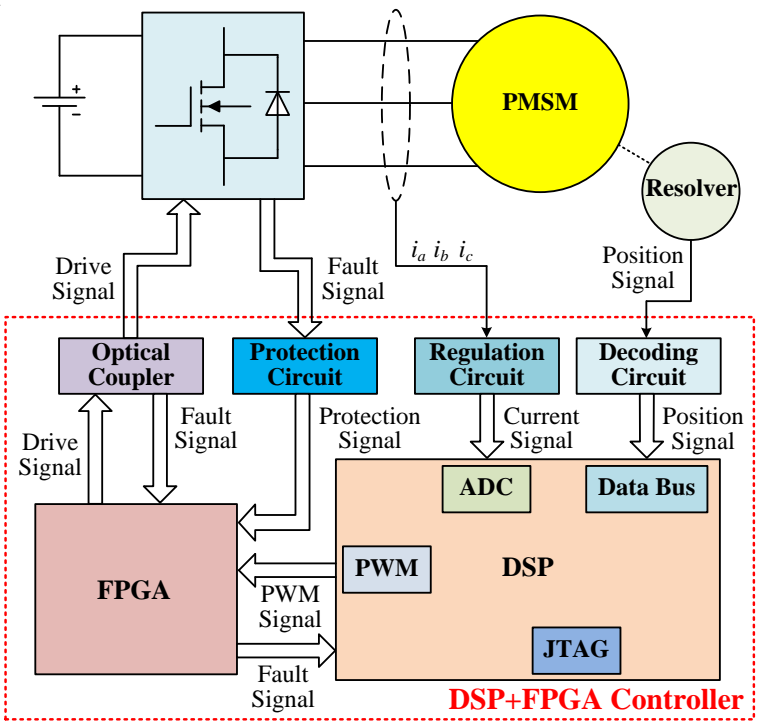

Fig. 22. Diagram of the experimental prototype.

In the process of experiments, using the proposed VCT control method, the motor can start and brake smoothly. To highlight the improvement of the proposed VCT control method, a comparison with the PI control method and direct compensation control method is made. Fig. 24-Fig. 26 give the experimental results of different control methods at the low speed of $1 \mathrm{rpm}$ with different loads $(50 \%, 100 \%$ and $200 \%$ of the rated load respectively), including load step changes. The speed ripple factor (SRF) is used to evaluate the effectiveness of the proposed control method for speed ripple reduction. In this paper, the SRF is defined as the ratio (percentage) of the peak-to-peak speed ripple to the speed reference. Fig. 27 shows the SRF values of different control methods with the rated load at the speed of $1 \mathrm{rpm}$.

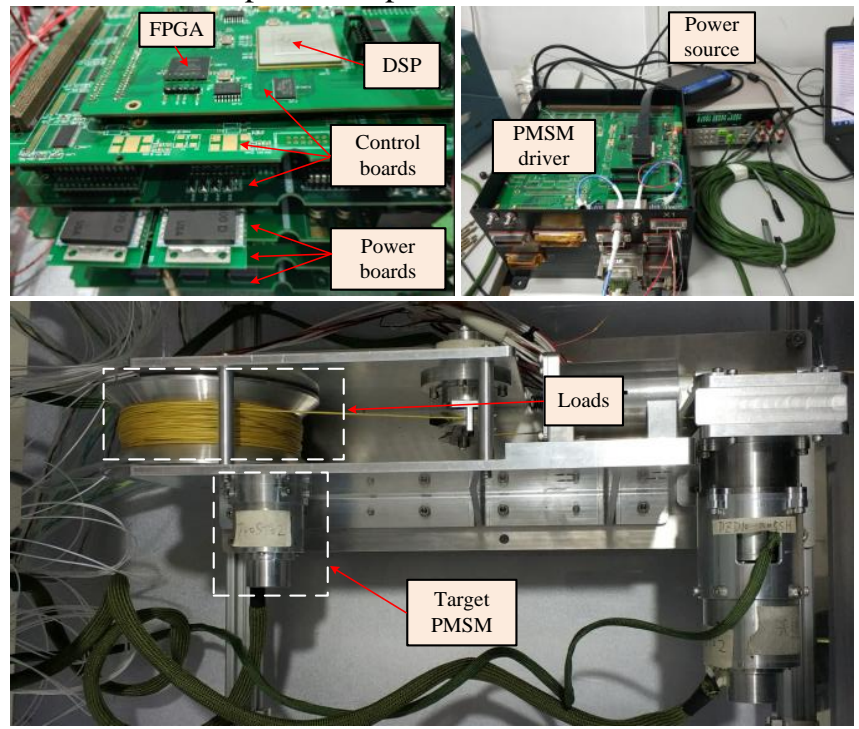

Fig. 23. Picture of the experimental prototype.
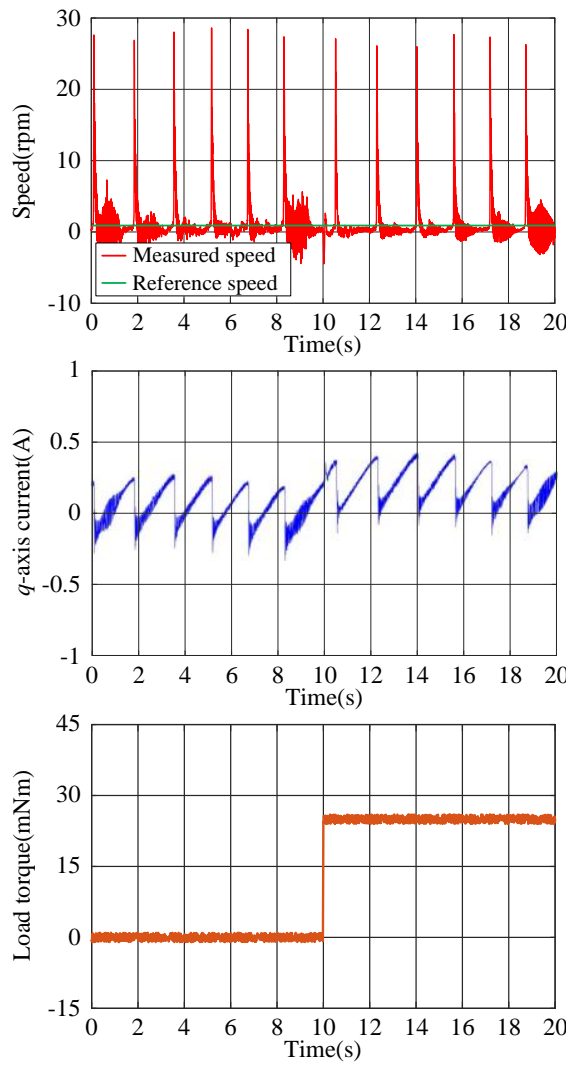

(a)
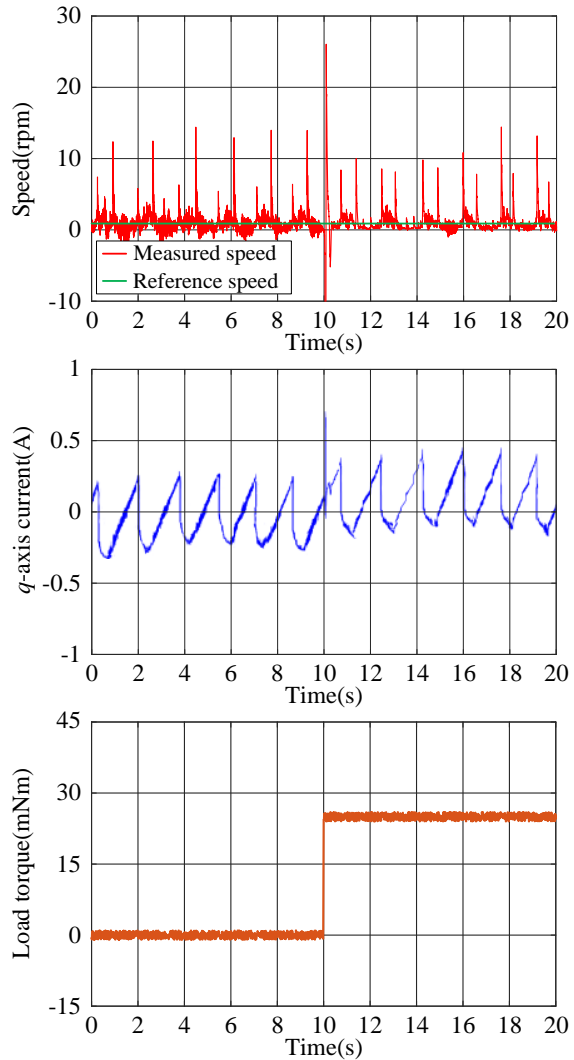

(b)
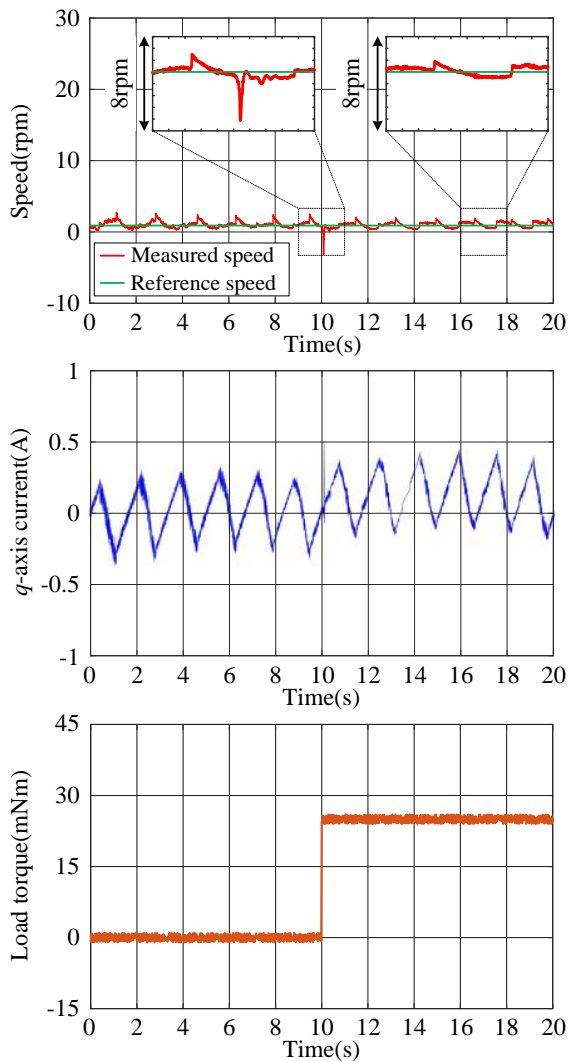

(c)

Fig. 24. Experimental results of different control methods at the speed of 1rpm with $50 \%$ of the rated load. (a) PI control method. (b) Direct compensation control method. (c) Proposed VCT control method. 

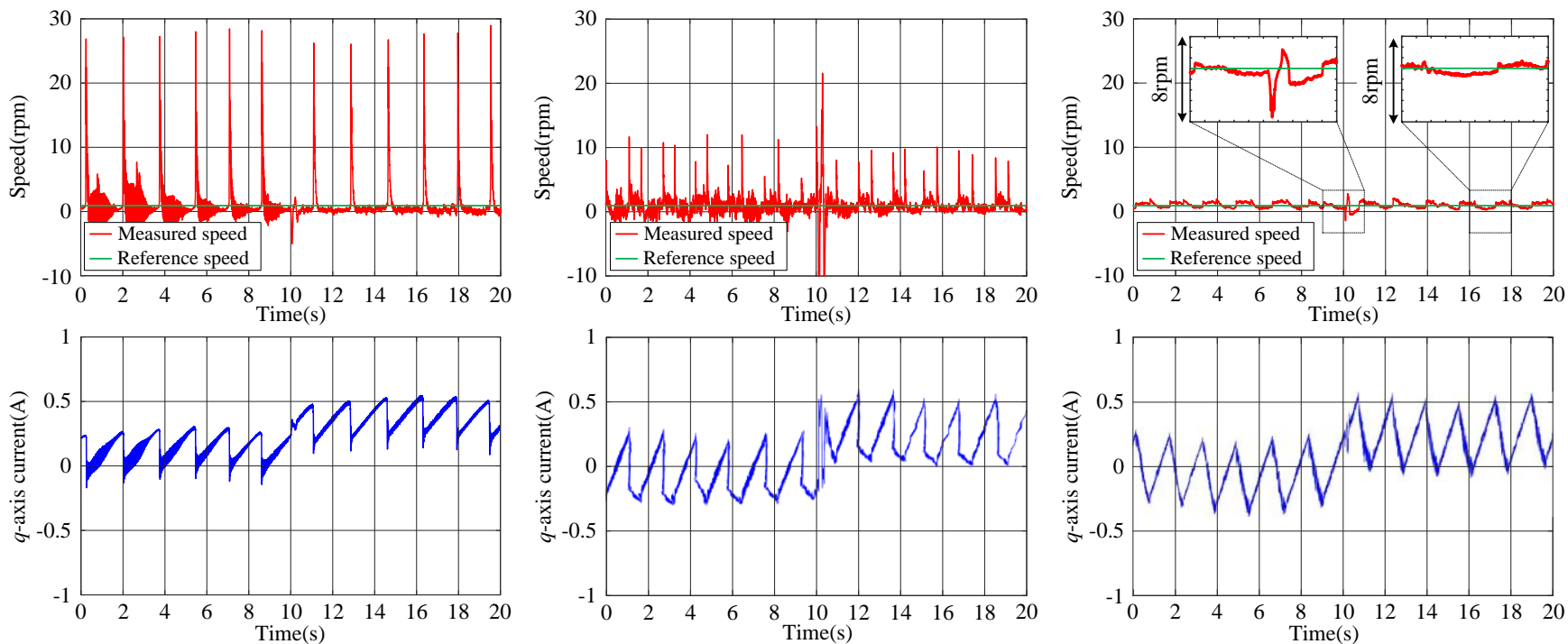

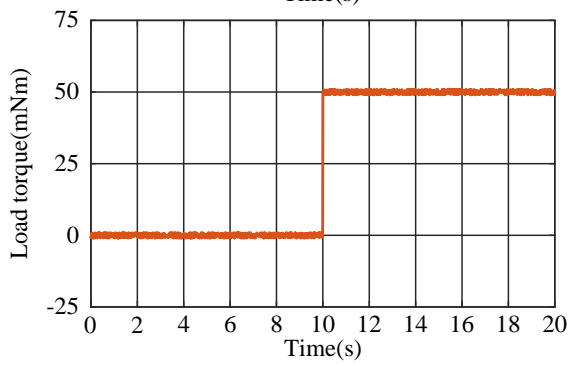

(a)

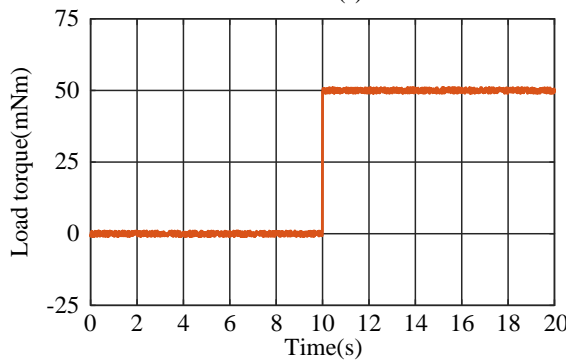

(b)

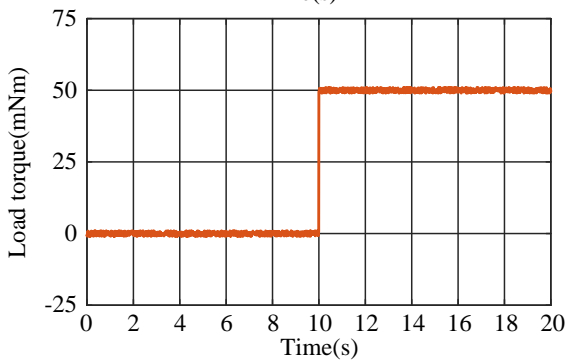

(c)

Fig. 25. Experimental results of different control methods at the speed of $1 \mathrm{rpm}$ with $100 \%$ of the rated load. (a) PI control method. (b) Direct compensation control method. (c) Proposed VCT control method.
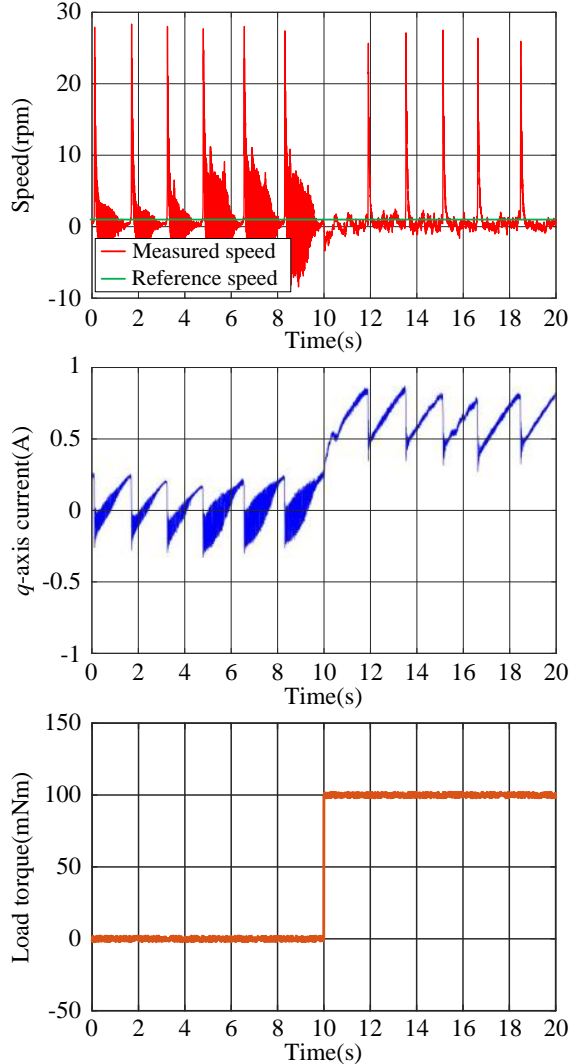

(a)
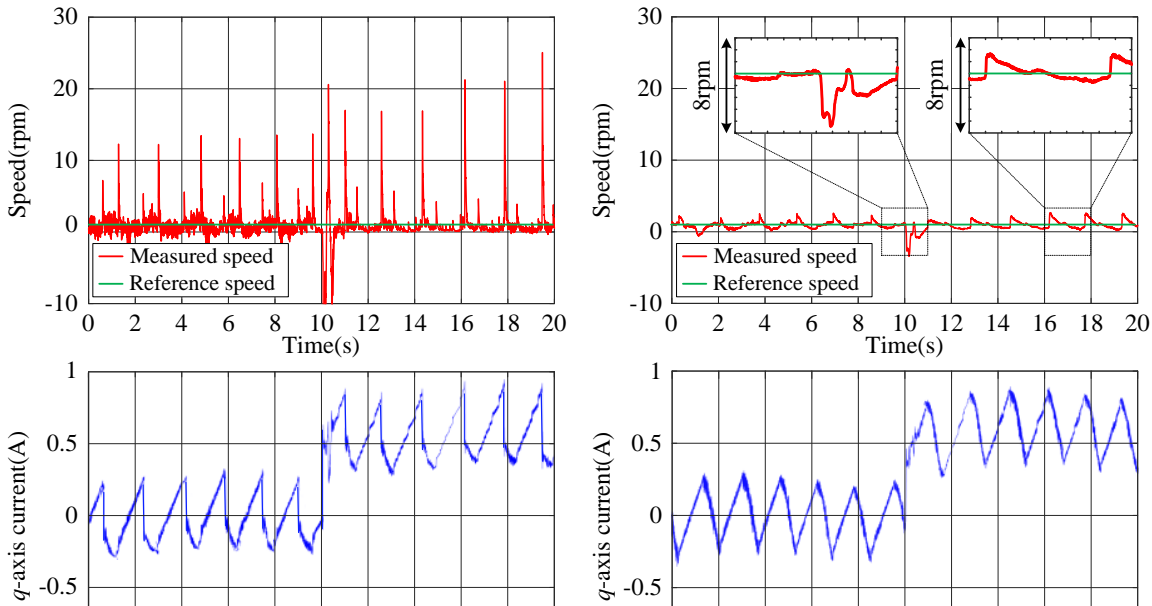

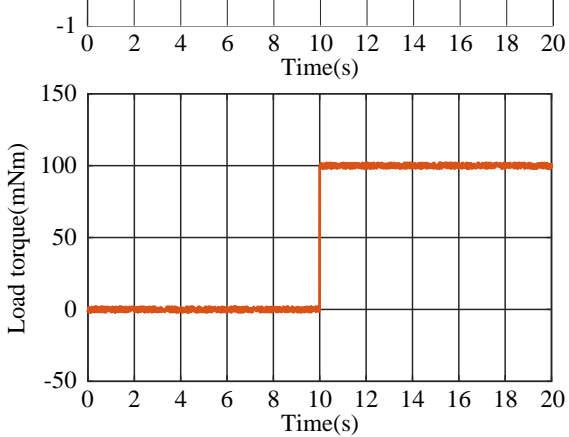

(b)

Fig. 26. Experimental results of different control methods at the speed of $1 \mathrm{rpm}$ with $200 \%$ of the rated load. (a) PI control method. (b) Direct compensation control method. (c) Proposed VCT control method. 
From Fig. 24(a), Fig. 25(a) and Fig. 26(a), using the PI control method, the motor starts to creep, and the speed ripple is very large (the SRF is about $2800 \%$ ). The frequency of creeping action is corresponding to the cogging torque. When the motor stays still in the process of creeping action due to the friction, the $q$-axis current keeps rising. When the motor moves, the $q$-axis current drops quickly, then the rotor stops again due to the friction.

From Fig. 24(b), Fig. 25(b) and Fig. 26(b), using the direct compensation control method, the speed ripple is reduced to some extent, but it is still large (the SRF at the low speed of $1 \mathrm{rpm}$ with the rated load is about $1000 \%$ ), and the motor also remains creeping. Owing to the compensation, the $q$-axis current drops slower compared with the PI control method.

From Fig. 24(c), Fig. 25(c) and Fig. 26(c), using the proposed VCT control method, the $q$-axis current is nearly sinusoidal rather than a saw-tooth shape, and the speed ripple is decreased significantly. The SRF at the low speed of $1 \mathrm{rpm}$ with the rated load is about $150 \%$, which is about $15 \%$ of that when using the direct compensate method, and about $5.35 \%$ of that when using the PI control method. And the creeping problem no longer exists.

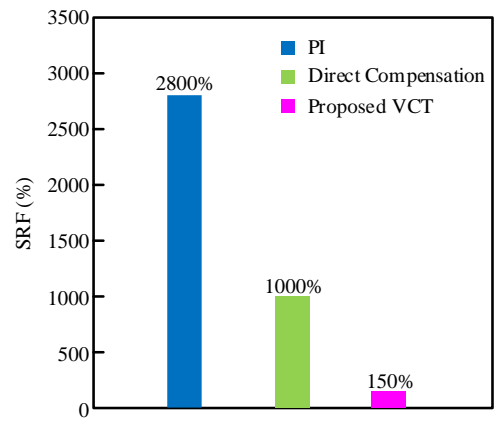

Fig. 27. Experimental results of SRF values of different control methods with the rated load at the speed of $1 \mathrm{rpm}$.

Additionally, from Fig. 24-Fig. 26, using the proposed VCT control method, when the load increases suddenly, the speed has a small drop but recovers quickly. Compared with other two control methods, the dynamic performance of the proposed control method is relatively better.

It can be concluded from the above experimental results that: (1) compared with other two control methods, at the low speed of $1 \mathrm{rpm}$, with different loads, even under the overload operation which would cause a certain magnetic saturation, the proposed control method has better performance, especially the static speed performance; (2) at the low speed of 1rpm, the target PMSM using the PI control method starts to creep, and the direct compensation method can relieve this problem, but the creeping problem still exists, while the proposed control method has a significant reduction of speed ripple and there is no creeping problem.

\section{CONCLUSION}

This paper proposes the VCT control method for the speed control of DD-PMSM servo system operating at low speeds. The proposed control method can effectively reduce the speed ripple caused by the cogging torque at low-speed operations, especially for the PMSM in this paper with a larger cogging torque (about $70 \%$ of the rated torque). The characteristic and effect of target PMSM's cogging torque are analyzed. And the principle of this proposed control method is investigated in detail. Based on this, its implementation is clearly presented. The study indicates that the effectiveness of this proposed control method is closely related to the virtual cogging torque and virtual damping. Moreover, it only requires knowing two basic kinds of information: the amplitude of actual cogging torque and the number of actual stable equilibrium points of the target PMSM, and the precise speed feedback is not needed. The simulation and experimental results from the prototype demonstrate that, compared with the PI and direct compensation control methods, the proposed control method not only can more effectively reduce the effect of large cogging torque on the speed ripple at low speeds, but also has the advantages of simple implementation and good adaptability.

\section{APPENDIX}

The parameters of target PMSM and driver in this paper are listed in Table II.

Table. II. Parameters of the target PMSM and driver in this paper.

\begin{tabular}{|c|c|c|c|c|c|}
\hline Parameters & Value & \multicolumn{3}{|c|}{ Parameters } & Value \\
\hline Rated voltage & $24 \mathrm{~V}$ & \multirow{8}{*}{$\begin{array}{l}\text { Speed } \\
\text { loop }\end{array}$} & \multicolumn{2}{|c|}{ Control period of speed loop } & $0.5 \mathrm{~ms}$ \\
\hline Rated current & $0.35 \mathrm{~A}$ & & \multirow{2}{*}{$\begin{array}{c}\text { PI } \\
\text { control method }\end{array}$} & Proportion coefficient & 1 \\
\hline Rated torque & $50 \mathrm{mNm}$ & & & Integral coefficient & 0.05 \\
\hline Rated speed & 1100rpm & & \multirow{2}{*}{$\begin{array}{l}\text { Direct compensation } \\
\text { control method }\end{array}$} & \multirow{2}{*}{ Compensation function } & \multirow{2}{*}{$0.035 \sin (36 \theta+\pi)$} \\
\hline Phase resistance & $11.5 \Omega$ & & & & \\
\hline Phase inductance & $4.78 \mathrm{mH}$ & & \multirow{2}{*}{$\begin{array}{c}\text { Proposed virtual cogging } \\
\text { torque control method }\end{array}$} & Virtual cogging torque coefficient $A$ & 600 \\
\hline Number of pole pairs & 6 & & & Virtual damping coefficient $k$ & 100 \\
\hline Magnet flux linkage & $0.018444 \mathrm{~Wb}$ & & \multicolumn{2}{|c|}{ Maximum $q$-axis current reference } & $2 \mathrm{~A}$ \\
\hline Mechanical inertia of motor & $1.86 \mathrm{~kg} \cdot \mathrm{mm}^{2}$ & \multirow{5}{*}{$\begin{array}{l}\text { Current } \\
\text { loop }\end{array}$} & \multicolumn{2}{|c|}{ Control period of current loop } & $0.05 \mathrm{~ms}$ \\
\hline Damping coefficient of motor & 0.0000011 & & \multirow{2}{*}{$\begin{array}{c}d \text {-axis } \\
\text { PI controller }\end{array}$} & Proportion coefficient & 41.15 \\
\hline Amplitude of cogging torque & $35 \mathrm{mNm}$ & & & Integral coefficient & 0.6 \\
\hline Number of stable equilibrium points & 36 & & \multirow{2}{*}{$\begin{array}{c}q \text {-axis } \\
\text { PI controller }\end{array}$} & Proportion coefficient & 41.15 \\
\hline DC bus voltage & $31 \mathrm{~V}$ & & & Integral coefficient & 0.6 \\
\hline
\end{tabular}




\section{REFERENCES}

[1] P. Pillay, R. Krishnan, "Control characteristics and speed controller design for a high- performance magnet synchronous motor drive," IEEE Trans. Power Electron., vol. 5, no. 2, pp. 151-159, Apr. 1990.

[2] R. Wrobel and P. H. Mellor, "Design considerations of a direct-drive brushless machine with concentrated windings," IEEE Trans. Energy Convers., vol. 23, no. 1, pp. 1-8, Mar. 2008.

[3] N. Nakao and K. Akatsu, "Suppressing pulsating torques: Torque ripple control for synchronous motors," IEEE Ind. Appl. Mag., vol. 20, no. 6 , pp. 33-44, Nov. 2014.

[4] Y. H. Xu, N. Parspour and U. Vollmer, "Torque ripple minimization using online estimation of the stator resistances with consideration of magnetic saturation," IEEE Trans. Ind. Electron., vol. 61, no. 9, pp. 5105-5114, Sep. 2014.

[5] F. Betin, G. A. Capolino, D. Casadei and B. Kawkabani, "Trends in electrical machines control: Samples for classical, sensorless and fault-tolerant techniques," IEEE Ind. Electron. Mag., vol. 8, no. 2, pp. 43-55, Jun. 2014.

[6] D. Flieller, N. K. Nguyen and P. Wira, "A self-learning solution for torque ripple reduction for non-sinusoidal permanent-magnet motor drives based on artificial neural networks," IEEE Trans. Ind. Electron., vol. 61, no. 2, pp. 655-666, Feb. 2014.

[7] D. M. Park and K. H. Kim, "Parameter-independent online compensation scheme for dead-time and inverter-nonlinearity in IPMSM drive through waveform analysis," IEEE Trans. Ind. Electron., vol. 61, no. 2, pp. 701-707, Feb. 2014.

[8] N. N. Chen, S. L. Ho and W. N. Fu, "Optimization of permanent magnet surface shapes of electric motors for minimization of cogging torque using FEM," IEEE Trans. Magn., vol. 46, no. 6, pp. 2478-2481, Jun. 2010.

[9] R. Islam, I. Husain, A. Fardoun and K. M. Laughlin, "Permanent magnet synchronous motor magnet designs with skewing for torque ripple and cogging torque reduction," IEEE Trans. Ind. Appl., vol. 45, no. 1, pp. 152-160, Feb. 2009.

[10] L. Zhu, S. Z. Jiang, Z. Q. Zhu and C. C. Chan, "Analytical methods for minimizing cogging torque in permanent magnet machines," IEEE Trans. Magn., vol. 45, no. 4, pp. 2023-2031, Apr. 2009.

[11] L. Parsa and L. Hao, "Interior permanent magnet motors with reduced torque pulsation," IEEE Trans. Ind. Electron., vol. 55, no. 2, pp. 602-609, Feb. 2008.

[12] M. Ashabani and Y. A. R. I. Mohamed, "Multiobjective shape optimization of segmented pole permanent magnet synchronous machines with improved torque characteristics," IEEE Trans. Magn., vol. 47, no. 4, pp. 795-804, Apr. 2011.

[13] A. Houari, A. Bouabdallah, A. Djerioui and M. Machmoum, "An Effective Compensation Technique for Speed Smoothness at Low-Speed Operation of PMSM Drives," IEEE Trans. Ind. Appl., vol. 54, no. 1, pp. 647-655, Jan. 2018.

[14] C. L. Xia, B. N. Ji and Y. Yan, "Smooth speed control for low speed high torque permanent magnet synchronous motor using proportional integral resonant controller," IEEE Trans. Ind. Electron., vol. 62, no. 4, pp. 2123-2134, Apr. 2015.

[15] W. Z. Qian, S. K. Panda and J. X. Xu, "Speed ripple minimization in PM synchronous motor using iterative learning control," IEEE Trans. Energy Convers., vol. 20, no. 1, pp. 53-61, Mar. 2005.

[16] G. D. Feng, C. Y. Lai and N. C. Kar, "A closed-loop fuzzy-logic-based current controller for PMSM torque ripple minimization using the magnitude of speed harmonic as the feedback control signal," IEEE Trans. Ind. Electron., vol. 64, no. 4, pp. 2642-2653, Apr. 2017.

[17] A. Mora, A. Orellana, J. Juliet and R. Cardenas, "Model predictive torque control for torque ripple compensation in variable speed PMSMs," IEEE Trans. Ind. Electron., vol. 63, no. 7, pp. 4584-4592, Jul. 2016.

[18] G. C. Zhu, L. A. Dessaint, O. Akhrif and A. Kaddouri, "Speed Tracking Control of a Permanent-Magnet Synchronous Motor with State and Load Torque Observer," IEEE Trans. Ind. Electron., vol. 47, no. 2, pp. 346-355, Apr. 2000.

[19] G. H. B. Foo and X. N. Zhang, "Constant switching frequency based direct torque control of interior permanent magnet synchronous motors with reduced ripples and fast torque dynamics," IEEE Trans. Power Electron., vol. 31, no. 9, pp. 6485-6493, Sep. 2016.
[20] W. Z. Qian, S. K. Panda and J. X. Xu, "Torque ripple minimization in PM synchronous motors using iterative learning control," IEEE Trans. Power Electron., vol. 19, no. 2, pp. 272-279, Mar. 2004.

[21] Y. Cho, K. B. Lee, J. H. Song and Y. I. Lee, "Torque-ripple minimization and fast dynamic scheme for torque predictive control of permanent-magnet synchronous motors," IEEE Trans. Power Electron., vol. 30, no. 4, pp. 2182-2190, Apr. 2015.

[22] S. Chai, L. P. Wang and E. Rogers, "A cascade MPC control structure for a PMSM with speed ripple minimization," IEEE Trans. Ind. Electron., vol. 60, no. 8, pp. 2978-2987, Aug. 2013.

[23] V. Petrovic, R. Ortega, A. M. Stankovic and G. Tadmor, "Design and implementation of an adaptive controller for torque ripple minimization in PM synchronous motors," IEEE Trans. Power Electron., vol. 15, no. 5, pp. 871-880, Sep. 2000.

[24] W. C. Gan and L. Qiu, "Torque and velocity ripple elimination of ac permanent magnet motor control systems using the internal model principle," IEEE Trans. Mechatronics., vol. 9, no. 2, pp. 436-447, Jun. 2004.

[25] K. Wang, P. Zhang, Y. C. Lin and D. L. Li, "Environmental adaptive design of joint for a lunar surface sampling arm," Spacecraft Environment Engineering, vol. 34, no. 5, pp. 482-489, Oct. 2017.

[26] D. H. Jung and I. J. Ha, "An efficient method for identifying the initial position of a PMSM with an incremental encoder," IEEE Trans. Ind. Electron., vol. 44, no. 4, pp. 682-685, Aug. 1998.

[27] X. Zhang, H. Y. Li, S. Y. Yang and M. Y. Ma, "Improved initial rotor position estimation for PMSM drives based on HF pulsating voltage signal injection," IEEE Trans. Ind. Electron., vol. 65, no. 6, pp. 4702-4713, Jul. 2018.

[28] T. Turker, U. Buyukkeles and A. F. Bakan, "A robust predictive current controller for PMSM drives," IEEE Trans. Ind. Electron., vol. 63, no. 6, pp. 3906-3914, Jan. 2016.

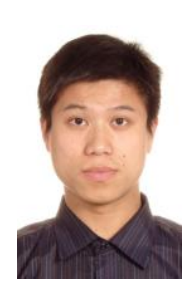

Feifei Bu (S'09, M'11, SM'19) was born in Maanshan, China, in 1984. He received the B.S. degree in electrical engineering from the Anhui University of Technology, Maanshan, China, in 2006, and the Ph.D. degree in electrical engineering from the Nanjing University of Aeronautics and Astronautics (NUAA), Nanjing, China, in 2014.

Since June 2014, he has been with the faculty of the Department of Electrical Engineering, NUAA, where he is currently an Associate Professor. From December 2018 to November 2019, he was a Visiting Scholar with the Power Electronics, Machine and Control Group (PEMC), University of Nottingham, Nottingham, UK. His main research interests include power electronics and electrical machines for standalone power systems, renewable energy generating systems, electric drive systems. He serves as an Associate Editor of the IET Renewable Power Generation and the IEEE Access.

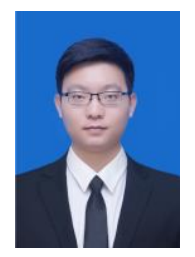

Zhida Yang was born in Jiangyin, Jiangsu Province, China, in 1995. He received the B.S. degree in Electrical Engineering from Nanjing University of Aeronautics and Astronautics (NUAA), Nanjing, China, in 2017. He is currently pursuing the Master's degree in Electrical Engineering in NUAA, Nanjing, China. His main research interests are motor control and power electronics.

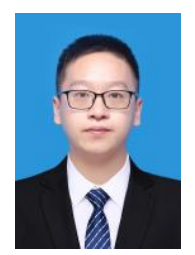

Yu Gao was born in Xinghua, Jiangsu Province, China, in 1993. He received the B.S. degree and the Master's degree in Electrical Engineering from Nanjing University of Aeronautics and Astronautics (NUAA), Nanjing, China, in 2016 and 2019. His main research interests are motor drive, power electronics and standalone power systems. 


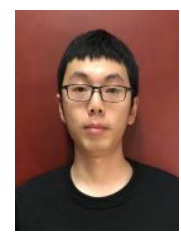

Zihao Pan was born in Suzhou, Jiangsu Province, China, in 1996. He received the B.S. degree in Electrical Engineering from Nanjing University of Aeronautics and Astronautics (NUAA), Nanjing, China, in 2018. He is currently pursuing the Master's degree in Electrical Engineering in NUAA, Nanjing, China. His main research interests are modulation technology and motor control.

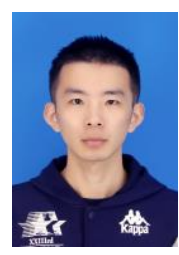

Tianyu Pu was born in Wuxi, Jiangsu Province, China, in 1995. He received the B.S. degree in Electrical Engineering from Nanjing University of Aeronautics and Astronautics (NUAA), Nanjing, China, in 2017. He is currently pursuing the Master's degree in Electrical Engineering in NUAA, Nanjing, China. His main research interests are power electronics, multiphase motor drive and modulation technology.

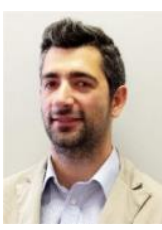

Michele Degano (M'15) received the Laurea degree in electrical engineering from the University of Trieste, Trieste, Italy, in 2011, and the Ph.D. degree in industrial engineering from the University of Padova, Padova, Italy, in 2015.

In 2015, he joined the Power Electronics, Machines and Control Group, The University of Nottingham, Nottingham, U.K., as a Research Fellow, where he is currently an Assistant Professor teaching advanced courses on electrical machines. His main research interests include design and optimization of permanent magnet machines, reluctance and permanent-magnet-assisted synchronous reluctance motors through genetic optimization techniques, for automotive and aerospace applications.

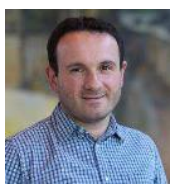

Chris Gerada (M'05, SM'12) received the Ph.D. degree in numerical modeling of electrical machines from the University of Nottingham, Nottingham, U.K., in 2005.

He subsequently worked as a Researcher with The University of Nottingham on high-performance electrical drives and on the design and modeling of electromagnetic actuators for aerospace applications. Since 2006, he has been the Project Manager of the GE Aviation Strategic Partnership. In 2008, he was appointed as a Lecturer in electrical machines; in 2011, as an Associate Professor; and in 2013, as a Professor at The University of Nottingham. His main research interests include the design and modeling of high-performance electric drives and machines. Prof. Gerada serves as an Associate Editor for the IEEE Transactions on Industry Applications and is the past Chair of the IEEE IES Electrical Machines Committee. 